This item was submitted to Loughborough's Research Repository by the author.

Items in Figshare are protected by copyright, with all rights reserved, unless otherwise indicated.

\title{
Surface engineering alumina armour ceramics with laser shock peening
}

PLEASE CITE THE PUBLISHED VERSION

https://doi.org/10.1016/j.matdes.2017.08.066

\section{PUBLISHER}

(c) Elsevier

\section{VERSION}

AM (Accepted Manuscript)

\section{PUBLISHER STATEMENT}

This work is made available according to the conditions of the Creative Commons Attribution-NonCommercialNoDerivatives 4.0 International (CC BY-NC-ND 4.0) licence. Full details of this licence are available at: https://creativecommons.org/licenses/by-nc-nd/4.0/

\section{LICENCE}

CC BY-NC-ND 4.0

\section{REPOSITORY RECORD}

Shukla, Pratik P., Stuart Robertson, Houzheng Wu, A. Telang, M. Kattoura, S. Nath, S.R. Mannava, V.K. Vasudevan, and Jonathan Lawrence. 2017. "Surface Engineering Alumina Armour Ceramics with Laser Shock Peening”. figshare. https://hdl.handle.net/2134/26769. 


\title{
Surface Engineering Alumina Armour Ceramics with Laser Shock Peening
}

\author{
P. Shukla ${ }^{1^{*}}$, S. Robertson ${ }^{2}$, H. $\mathbf{W u}^{2}$, A. Telang ${ }^{3}$, M. Kattoura ${ }^{3}$, S. Nath ${ }^{1}$, S. R. \\ Mannava $^{3}$, V. K. Vasudevan ${ }^{3}$, and J. Lawrence ${ }^{1}$ \\ ${ }^{1 *}$ Coventry University, School of Mechanical, Aerospace and Automotive Engineering, Faculty of \\ Engineering, Environment and Computing, Priory Street, Coventry, CV1 5FB, United Kingdom, \\ Email:pratik.shukla@talk21.com
}

${ }^{2}$ Department of Materials, Loughborough University, Loughborough, LE11 3TU, United Kingdom

${ }^{3}$ Department of Mechanical and Materials Engineering, University of Cincinnati, Ohio, OH452210072, USA

Citation: Shukla, P., Robertson, S., Wu, H., Telang, A., Kattoura, M., Nath, S., Mannava, S.R., Vasudevan, V.K., and J. Lawrence, (2017), 'Surface Engineering Alumina Armour Ceramics with Laser Shock Peening', Materials and Design, 134, 523 - 538. 


\begin{abstract}
Laser shock peening (LSP) of $\mathrm{Al}_{2} \mathrm{O}_{3}$ armour ceramics is reported for the first-time. A 10J, 8ns, pulsed Nd:YAG laser with a 532nm wavelength was employed. The hardness, $\mathrm{K}_{\mathrm{lc}}$, fracture morphology, topography, surface residual stresses and microstructures were investigated. The results showed an increase in the surface hardness by $10 \%$ which was confirmed by a reduction in Vickers indentations size by $5 \%$. The respective flaw sizes of the Vickers indentations were also reduced $(10.5 \%)$ and inherently increased the $\mathrm{K}_{\mathrm{Ic}}(12 \%)$. Residual stress state by $\mathrm{X}$-ray diffraction method showed an average stress of $-64 \mathrm{MPa}$ after LSP, whilst the untreated surface stress measured $+219 \mathrm{MPa}$. Further verification with the fluorescence method revealed surface relaxation with a maximum residual stress of $-172 \mathrm{MPa}$ after LSP of the $\mathrm{Al}_{2} \mathrm{O}_{3}$ armour ceramic. These findings are attributed to a microstructural refinement, grain size reduction and an induction of compressive stress that was relaxing the top/near surface layer from the pre-existing tensile stresses after LSP. Further process refinement/optimization will provide better control of the surface properties and will act as a strengthening technique to improve the performance of armour ceramics to stop bullets for a longer period of time and protect the end-users.
\end{abstract}

Keywords: LSP; Ceramics; $\mathrm{Al}_{2} \mathrm{O}_{3}$; Hardness; $\mathrm{K}_{\mathrm{Ic}}$, Fracture Toughness, Residual Stress 


\section{Introduction}

Engineering ceramics are hard, brittle and difficult to process, particularly when a high intensity energy source such as a laser is applied [1 - 7]. Even so, considerable work has been published on processing these materials with a continuous wave (CW) laser beam [3 - 7]. The industrial applications of ceramics are namely: fuel cells to high performance disk brakes; automotive engine parts; rocket nozzles; tappet valves to armed-force and military armours. This work is focused on surface engineering $\mathrm{Al}_{2} \mathrm{O}_{3}$ armour ceramics using laser shock peening (LSP) for side plate of a bullet-proof vest. Traditionally, armours have been made from steels but with increases in the size of projectile piercing, there is more demand of increasing the armour thickness to defeat the projectiles. With that said, it is ever so difficult to increase the thickness of the steel armours because the weight will equivalently increase at the same time, thus, making it difficult to use [8]. Previous work has also included ceramic/metal composite armour systems that were developed and tested for ballistic strength [9 - 11], and weight reduction so they can defeat the modern armour piercing projectiles without being so heavy and bulky [8]. This has not only helped to make it practically possible for a bullet proof vest application to exist but also for tanks and other moving surface vehicles. Ceramic armours tend to hold a considerable importance in the modern armour systems [11]. In comparison to metallic armours, the ceramic counterparts absorb energy with a different mechanism. Whilst metals plastically deform as the impact energy is received, the ceramics absorb the same through fractures [11]. The ceramic armour is usually assembled or packed with either a monolithic ceramic or a composite of metal-ceramic plate with either a $\operatorname{Kevlar}^{\mathrm{TM}}$, or other laminated polyethylene backing. This sandwich is then packed with a ballistic nylon as a cover, forming either a front, back or a side plate. The complete assembly helps to absorb energy of up to $1000 \mathrm{~m} / \mathrm{sec}$, whereby, the ceramic is fractured and the energy is absorbed by the backing material. Many different ceramic systems can be used such as oxides; nitrides; carbides; borides and their mixtures. One type of ceramic that is commonly used for this type of application is Alumina $\left(\mathrm{Al}_{2} \mathrm{O}_{3}\right)$ ceramic in particular [11 - 14]. The physical properties such as low density (2 to $3.5 \mathrm{~g} \mathrm{~cm}^{-3}$ ) of this ceramic are ideal for ballistic applications, thus, low weight, high hardness, controlled microstructures to ensure durability and performance. Such properties will make it capable of defeating high velocity projectiles and enable the ceramic armour to be five times stronger and $70 \%$ lightweight than the metallic armours. Ceramic ballistic armours usually fracture after exposure to $0.30 \mathrm{~mm}$ calibre rifle bullet after seven impacts. Thereafter, the plates cannot be mended/maintained or serviced for re-use. Thus, it leads to their disposal, which would ultimately be a waste and a costly investment. On account of this, LSP surface treatment was employed to investigate if further strengthening could be obtained to lengthen its functional life. In 
doing so, it would not only avoid early disposal but would also contribute to saving lives of its enduser, namely: police, soldiers in the armed-forces as well as vehicle armours.

Considerable research has been conducted using CW lasers to surface treat ceramics to enhance their properties. It was established that crack-free surface treatment can be obtained by applying $\mathrm{CO}_{2}$ lasers [7, 15 - 17]. Surface and bulk properties such as hardness [2], fracture toughness [3 $6]$, wear and friction [17], bending strength and surface morphology [18, 19], were improved as result of the laser surface treatment. Another rare piece of research that employed laser surface treatment to strengthen a $\mathrm{Si}_{3} \mathrm{~N}_{4}$ ceramic bullet proof vest was in the work of Harris et. al. [20]. They explored the bond strength as result of three surface conditions: as-fired; air re-fired and $\mathrm{KrF}$ laser surface processing. X-ray photoelectron spectroscopy indicated both treatments had oxidised the surface and the laser processed surface also had a greater concentration of hydroxyl groups. The wettability of both surfaces had improved and the laser processed surface was found to be highly hydrophilic. Mechanical testing of joints prepared with this technique showed highest strength in tension, with the focus of failure being cohesive preparation of the surface was conducted using three techniques.

Pulsed lasers have also been adopted to surface engineer ceramics [21 - 37]. A pulsed Nd: YAG pulsed laser and a TEA CO 2 pulsed laser (100 ns) was used to improve the fractured surfaces of Iranian ceramic for structural applications [19]. Laser re-melting and re-solidification was reported by Su et.al. [21]. Authors produced a defect-free surface on $\mathrm{Al}_{2} \mathrm{O}_{3} / \mathrm{Er}_{3} \mathrm{Al}_{5} \mathrm{O}_{12}$ ceramic and improved the microstructure. LSP is also a well-known pulsed process to surface treat metals/alloys, however, it is usually employed with assistance of two different layers (water and an absorptive layer) $[22,23]$. It is also possible to apply the technique without the use of water confinement layer [24], and by solely using the water as a single confinement layer [25 - 27]. Using the LSP technology much progress has been undertaken to improve the properties of metallic materials. Those are namely, fatigue life [28 - 29], fracture toughness [29, 30] hardness and wear [31 - 32], tensile properties [33], stress corrosion behaviour [35 - 36]; residual stress [37 - 38]; material microstructure respectively [39 - 40], using LSP as an independent technology and recently the introduction of hybrid laser shock peening [41].

Despite this, LSP of ceramic materials is extremely rare due to their crack sensitivity, brittleness and strong covalent bonding which makes them difficult to plastically deform $[1,2]$, thus, the conventional benefits obtained with metals and alloys from LSP are not easily obtainable with difficult to process ceramics. Nevertheless, previous work has demonstrated some improvement in certain material properties such as hardness improvement $[30,42,43]$, fracture toughness $\left(\mathrm{K}_{\mathrm{Ic}}\right)$ [44] with selected processing parameters. This research is focused on the feasibility of 
strengthening $\mathrm{Al}_{2} \mathrm{O}_{3}$ ballistic armour plates for a bulletproof vest application. Upon applying this superior surface engineering treatment, it is postulated that improvement in the ballistic strength and enhanced service life will be obtained. This directly will help to save lives of end-users with enhanced surface properties leading to improved functional life.

\section{Experimentation and Analysis}

\subsection{Material Details}

The $\mathrm{Al}_{2} \mathrm{O}_{3}$ ceramic armour plates were processed using hot isostatic pressing. A typical level 4 plate with a dimensional size of $150 \mathrm{~mm} \times 200 \mathrm{~mm} \times 15 \mathrm{~mm}$ (width $\times$ length $\times$ thickness) was used for the investigation (see Figure 1 (a-d)). The $\mathrm{Al}_{2} \mathrm{O}_{3}$ ceramic armour plates were collectively packed with a nylon cover and adhesive bonded to a Kevlar ${ }^{\mathrm{TM}}$ backing as shown in Figure 1(b). Twelve $\mathrm{Al}_{2} \mathrm{O}_{3}$ ceramic blocks makes-up a side plate of a bullet-proof vest as shown in Figure 1 (a and $\mathrm{c}$ ). These $50 \mathrm{~mm} \times 50 \mathrm{~mm}$ square blocks were used with a thickness of $9 \mathrm{~mm}$ (see Figure 1(d)) which were laser shock peened each and re-packed together to make up the $\mathrm{Al}_{2} \mathrm{O}_{3}$ ceramic armour side plate. The average surface roughness after 5 measurements of the $\mathrm{Al}_{2} \mathrm{O}_{3}$ armour plate was $\mathrm{Ra}$ $0.56 \mu \mathrm{m}$ and $\mathrm{Sa} 4.54 \mu \mathrm{m}$. The surface hardness was measured to be $1118 \mathrm{HV}$ with plane strain surface fracture toughness $\left(\mathrm{K}_{\mathrm{lc}}\right)$ of $1.23 \mathrm{MPa} . \mathrm{m}^{1 / 2}$ under the applied conditions.

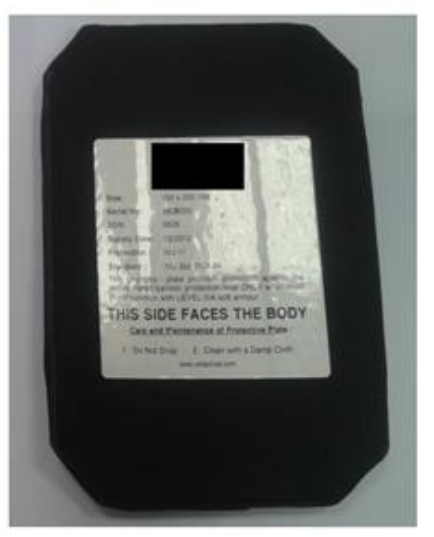

(a)

\section{Kevlar}

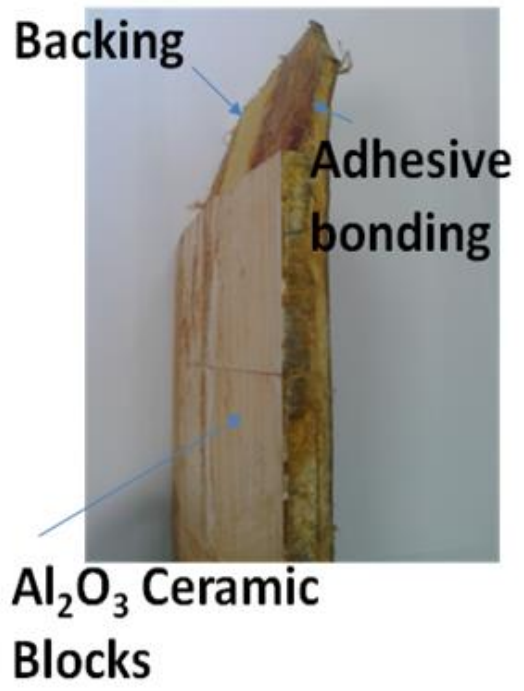

(b) 


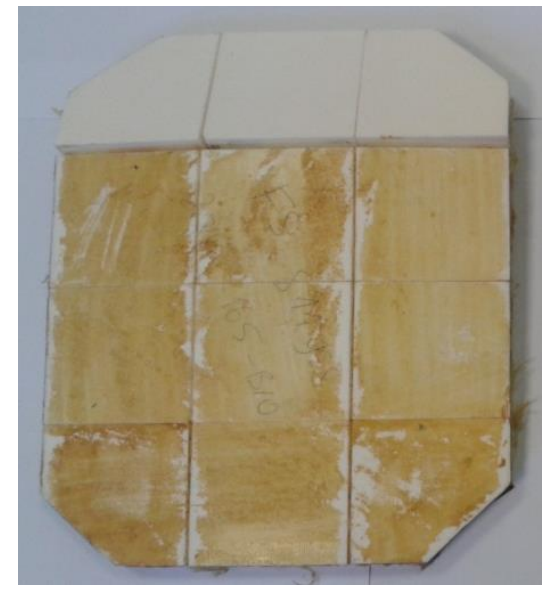

(c)

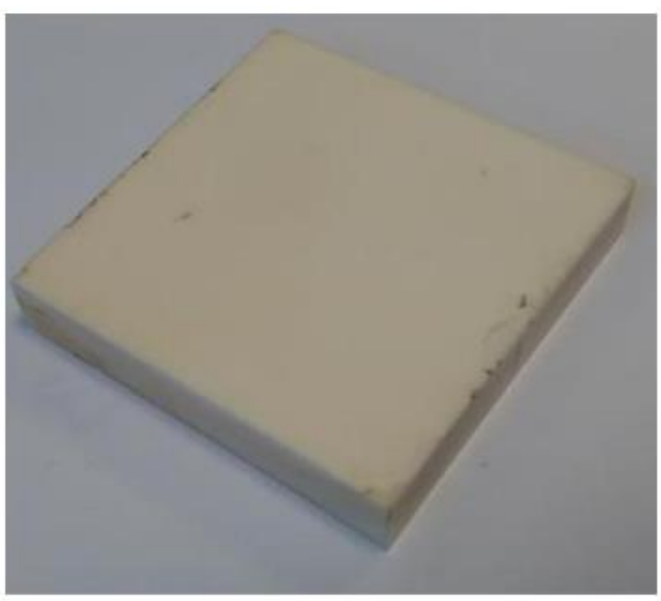

(d)

Figure 1 Optical images of the completely packed $\mathrm{Al}_{2} \mathrm{O}_{3}$ ceramic armour in (a); adhesive bonded blocks to a Kevlar ${ }^{T M}$ backing in (b); the side plate made up with 12 individual $\mathrm{Al}_{2} \mathrm{O}_{3}$ blocks in (c) and the single $\mathrm{Al}_{2} \mathrm{O}_{3}$ ceramic block which was prepared for LSP.

\subsection{Laser Shock Peening Experimentation}

Experiments were conducted using an ultra-high intensity Nd:YAG laser (Litron; LPY10J, ultra-high energy pulsed Nd:YAG Laser; Rugby; UK), funded from the Engineering and Physical Sciences research Council (EPSRC) laser loan-pool scheme. The system exerted an average maximum power of $10 \mathrm{~J}$, delivered at $5 \mathrm{~Hz}$ in $8 \mathrm{~ns}$ pulse duration. The laser beam comprised of a flat-top profile and a divergence angle of $0.5 \mathrm{mrad}$. The beam was focused from a raw $25 \mathrm{~mm}$ to $2.5 \mathrm{~mm}$ spot size using a $50 \mathrm{~mm}$ diameter fused silica lens. The LSP pulses were distributed at equal distance $(10 \mathrm{~mm}$ offset) over the surface area of the sample without any overlap to understand the effect and to avoid further thermal shock which may lead to fractures and cracking (see Figure 2(a)). The laser was set-up to operate at $532 \mathrm{~nm}$ wavelength, with a pulse repetition rate (PRR) of $5 \mathrm{~Hz}$, and q-switch delays of $215 \mu$ s to surface engineer the $\mathrm{Al}_{2} \mathrm{O}_{3}$ ceramic bullet proof ceramic. Energy density of 1.607 $\mathrm{J} / \mathrm{cm}^{2}$ was applied at the work-piece with $78 \mathrm{~mJ}$ per pulse that was delivered 5 times over the same spot and exhibited a crack-free surface treatment. This exhibited a radiance density (laser beam brightness) of $76.34 \mathrm{~mJ} . \mathrm{cm}^{2} . \mathrm{Sr}^{-1}$. $\mu \mathrm{m}$ per pulse and was determined using the equation published in our previous work [45]. The initial experiments demonstrated that the use of absorptive layer with laser shock peening did not affect the material, and rather, it required higher energy to penetrate into the material. However, the use of a black ink layer was suitable based on our previous work [2]. Thus, the method was adopted as a confinement layer (see Figure 2). De-ionized water was used to flow over the top of the sample with a continuous circular feed (see Figure 1(a-c)). 


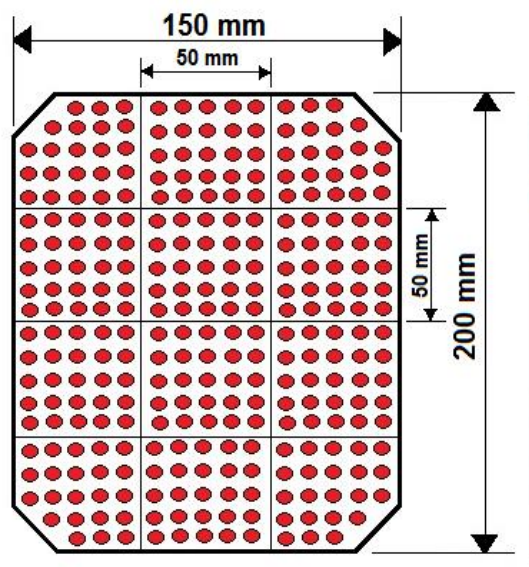

(a)

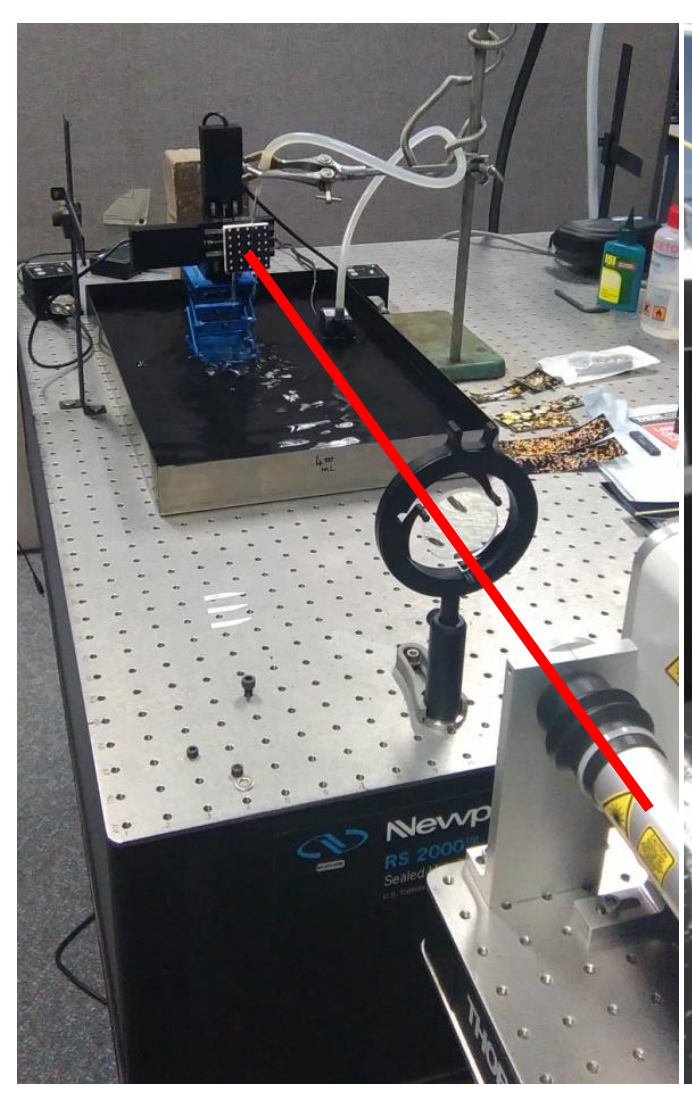

(c)

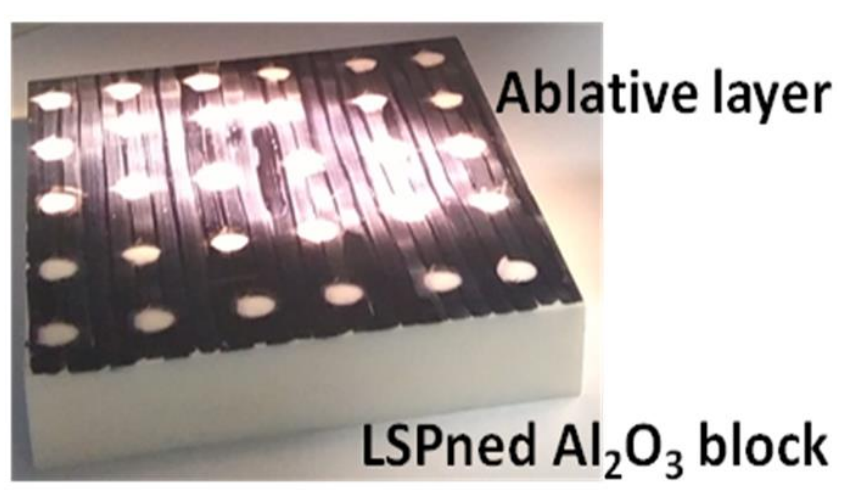

(b)

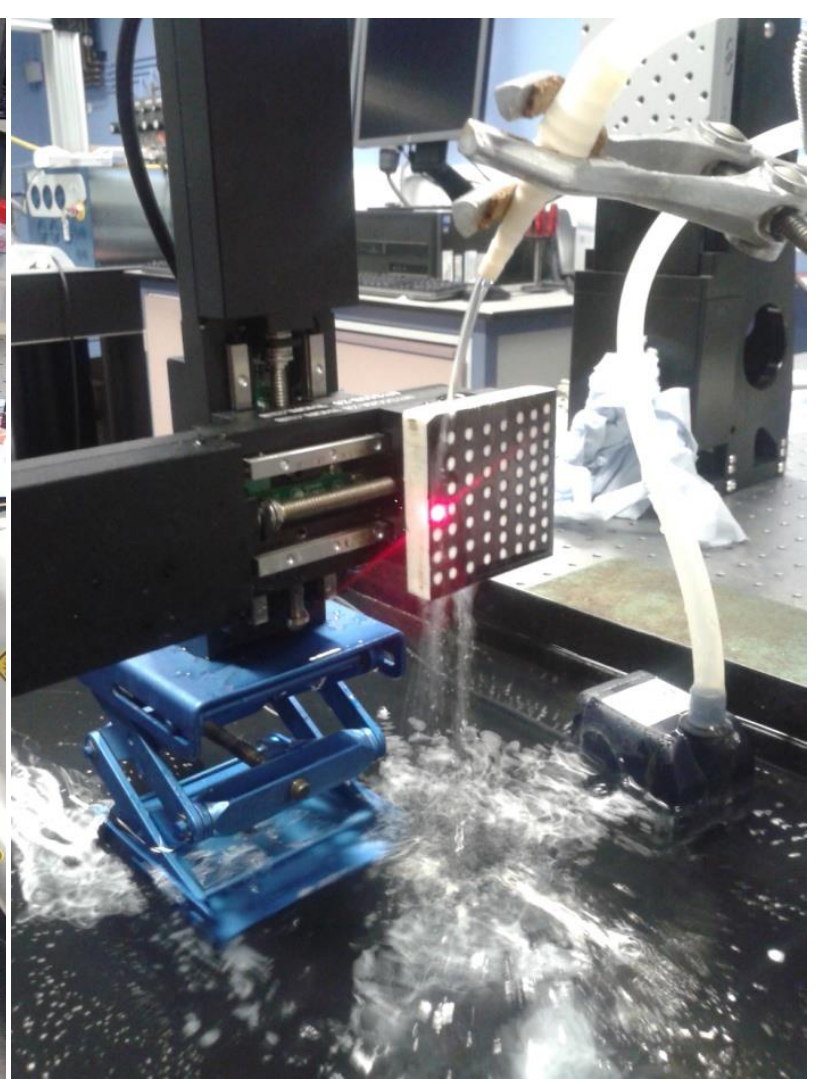

(d)

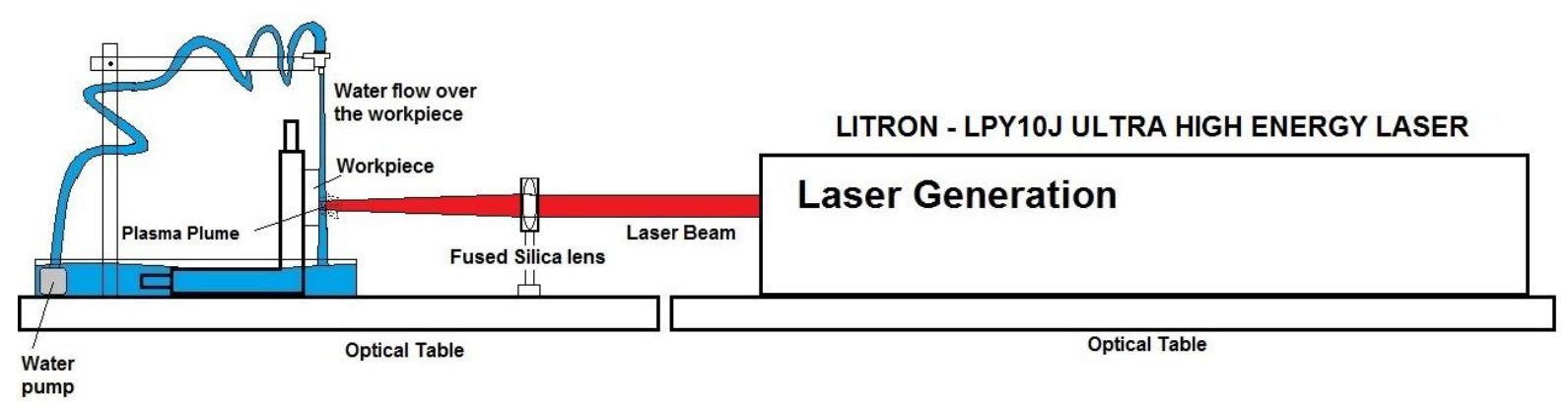


Figure 2 LSP strategy adopted for the surface engineering treatment in (a) $\mathrm{Al}_{2} \mathrm{O}_{3}$ armour ceramic plates after LSP in (b); beam delivery for LSP in (c); the arrangement of the ablative and confinement layers in (d); and (e) a schematic arrangement of the laser and the work piece, the motion system and the water confinement layer.

\subsection{Characterization Techniques}

\subsubsection{Macro and Microstructure}

Prior to any analysis and LSP surface treatment, the ceramic was polished to an acceptable standard so that it is free from surface defects. Using a Leica microscope (DM2700M; Milton Keynes, U.K.), crack detection was initially conducted to determine and establish a crack-free LSP treatment. The $\mathrm{Al}_{2} \mathrm{O}_{3}$ armour ceramic samples were coated with a sputter coating for the microstructural analysis using a scanning electron microscope ((SEM/EDS): Leo-1455VP; Cambridge, England). A thin black ink layer was also applied to the treated surfaces to detect any type of cracks that might have occurred after the LSP treatment. In order to observe the microstructure, a thermal etching technique was adopted, whereby, the $\mathrm{Al}_{2} \mathrm{O}_{3}$ armour ceramic was heated to $1500^{\circ} \mathrm{C}$ for 40 minutes and left to cool at $10^{\circ} \mathrm{C}$ minute within a high temperature furnace. This revealed the microstructure for grain measurements which was conducted using a line interception technique. An average of the grains boundary interaction was measured from three lines each in $\mathrm{x}$ and $\mathrm{y}$ direction (60 $\mu \mathrm{m}$ in length), drawn on the SEM micrographs. The average Grain intercept (AGl) was determined using Equation 1 and grain sizes were measured using Equation 2.

$\mathrm{AGI}=\frac{\text { Number of grain intercepts }(G i}{\text { Length of the line }(l)}$

Grain Size $=\frac{G i}{l}$

\subsubsection{Residual Stress Measurements and Phase Detection}

Proto LXRD system for residual stress measurement was employed for determination of residual stress at two orthogonal directions $0^{\circ}$ and $90^{\circ} \mathrm{Phi}$ angle for both the untreated and laser shock peened surfaces. Residual stresses were analysed in two orthogonal directions $\left(0^{\circ}\right.$ and $90^{\circ} \mathrm{Phi}$ angles) with a conventional X-ray diffraction using $\sin ^{2} \Psi$ technique with a Proto LXRD instrument (single axis goniometer with $\Omega$ geometry. Alignment of instruments was checked before each set of measurements with a standard titanium sample in accordance with ASTM E915-96 (verifying the alignment of X-ray diffraction instrumentation for residual stress measurement). Details of the 
residual stress measurement parameters are provided in Table 1. Verification of the residual stress with XRD was also conducted using fluorescence microscope (Hiriba, Japan). Multiple scans were applied with a $633 \mathrm{~nm} \mathrm{He}-\mathrm{Ne}$ laser within a spectrum of $14240-14550 \mathrm{Cm}^{-1}$. A 50 lens was employed which exhibited a $1 \mu \mathrm{m}$ beam diameter to detect the onset of residual stresses from the untreated to the laser shock peened zone. A detailed analysis of the phase evolution was carried out by X-ray diffraction (XRD) technique (Bruker D8 Discover, Germany) with Cu $K_{\alpha}$ radiation (wavelength $\approx 0.15418 \mathrm{~nm}$ ) at a scanning speed of $0.02 \%$ s. The X-ray source was operated at an accelerating voltage of $40 \mathrm{kV}$ and current of $25 \mathrm{~mA}$.

Table 1 XRD Parameters for residual stress measurement.

\begin{tabular}{|c|c|}
\hline \multicolumn{1}{|c|}{ Item } & Description \\
\hline Detector & PSSD (Position sensitive scintillation detector), \\
$20^{\circ} 2 \theta$ range \\
\hline Radiation & Cu Ka1 $\left(\lambda=1.541 \mathrm{~A}^{\circ}\right)$ \\
\hline Filter & $\mathrm{Ni}$ \\
\hline Tilt Angles (Beta Angles) & $0^{\circ}, \pm 0.29^{\circ}, \pm 6.99^{\circ}, \pm 12.86^{\circ}, \pm 17.0^{\circ}, \pm 23.0^{\circ}$ \\
\hline Aperture size (diameter) & $2 \mathrm{~mm}$ \\
\hline Plane (Bragg's Angle) & $\{4010\}$ set of planes. Bragg's angle: $146^{\circ}$ \\
\hline
\end{tabular}

\subsubsection{Hardness, Flaw Size and Fracture Toughness $\left(K_{l c}\right)$ Measurements}

The surface hardness was measured with a Vickers indentation technique [46]. Plane strain fracture toughness $\left(\mathrm{K}_{\mathrm{Ic}}\right)$ was measured by adopting the Vickers indentation technique [47 - 48]. There are several equations which could be used for the $\mathrm{K}_{\mathrm{lc}}$ calculation. Since the indentation load was significantly high, it is likely that a median half penny-shaped crack geometry will be produced and so equations 3 to 12 can potentially be utilised (see Table 2): 
Table 2 The equations used to calculate the $K_{1 c}$ for advanced ceramics.

\begin{tabular}{|c|c|}
\hline $\mathrm{K}_{1 \mathrm{c}}=0.0101 \mathrm{P} /\left(\mathrm{ac}^{1 / 2}\right)$ & Lawn \& Swain [49] \\
\hline $\mathrm{K}_{1 \mathrm{c}}=0.0724 \mathrm{P} / \mathrm{c}^{3 / 2}$ & Lawn \& Fuller [50] \\
\hline $\mathrm{K}_{1 \mathrm{c}}=0.0515 \mathrm{P} / \mathrm{C}^{3 / 2}$ & Evans \& Charles [51] \\
\hline$K_{1 c}=0.0134(E / H v)^{1 / 2}\left(P / c^{3 / 2}\right)$ & $\begin{array}{l}\text { Lawn, Evans \& Marshall } \\
\text { [52] }\end{array}$ \\
\hline $\mathrm{K}_{1 \mathrm{c}}=0.0330(\mathrm{E} / \mathrm{Hv})^{2 / 5}\left(\mathrm{P} / \mathrm{c}^{3 / 2}\right)$ & $\begin{array}{l}\text { Niihara, Morena and } \\
\text { Hasselman [53] }\end{array}$ \\
\hline$K_{1 c}=0.0363(E / H v)^{2 / 5}\left(P / a^{1.5}\right)(a / c)^{1.56}$ & Lankford [54] \\
\hline $\mathrm{K}_{1 \mathrm{c}}=0.095(\mathrm{E} / \mathrm{Hv})^{2 / 3}\left(\mathrm{P} / \mathrm{c}^{3 / 2}\right)$ & Laugier [54] \\
\hline$K_{1 c}=0.022(E / H v)^{2 / 3}\left(P / c^{3 / 2}\right)$ & Laugier [54] \\
\hline $\mathrm{K}_{1 \mathrm{c}}=0.035(\mathrm{E} / \mathrm{Hv})^{1 / 4}\left(\mathrm{P} / \mathrm{c}^{3 / 2}\right)$ & Tanaka [55] \\
\hline $\mathrm{K}_{1 \mathrm{c}}=0.016(\mathrm{E} / \mathrm{Hv})^{1 / 2}\left(\mathrm{P} / \mathrm{c}^{3 / 2}\right)$ & $\begin{array}{l}\text { Anstis, Chantikul, Lawn \& } \\
\text { Marshall [56] }\end{array}$ \\
\hline
\end{tabular}

Where $P$ is load $(\mathrm{kg}), c$ is average flaw size $(\mu \mathrm{m}), a$ is $2 c, m$ is length $(m), H V$ is the Vickers material hardness value and $E$ is the Young's modulus. For this investigation, the indentation load applied was $50 \mathrm{Kg}$ as 10 indentation tests were recorded from which an average was obtained. The selected equation herein was equation 10, where 0.016 is materials empirical value (no units). This was employed because it was successfully applied in previous studies focused on laser surface treatment of engineering ceramics [3 - 5] using equation:

\section{Results and Discussion}

\subsection{Establishment of Crack-free Laser Shock Peening Technique for $\mathrm{Al}_{2} \mathrm{O}_{3} \mathrm{Armour} \mathrm{Ceramics}$}

After applying the black ink layer for crack detection on the surface of the $\mathrm{Al}_{2} \mathrm{O}_{3}$ armour ceramic plates, light was made to shine under an optical microscope. This enabled the detection of any surface cracks that resulted from the LSP surface treatment. Figure 3 (a) to (c) are examples of the macro-structures of different area of laser shock peened zones. The features presented in the images are as result of the ink travelling in-between the agglomerates and their respective boundaries are evident. Figure 3(d) shows an optical image of the laser shock peened area at lower resolution - demonstrating the removal of the ablative layer after LSP. Figure 3(e) illustrated the use of ink layer for crack detection. As evident, there are no cracks present from observing the inked surfaces of the laser shock peened surface treatment. This indicated that the surface was 
firstly undamaged, and secondly, the surface was valid for further investigation of the microstructure, and aforementioned surface properties proposed for this study.

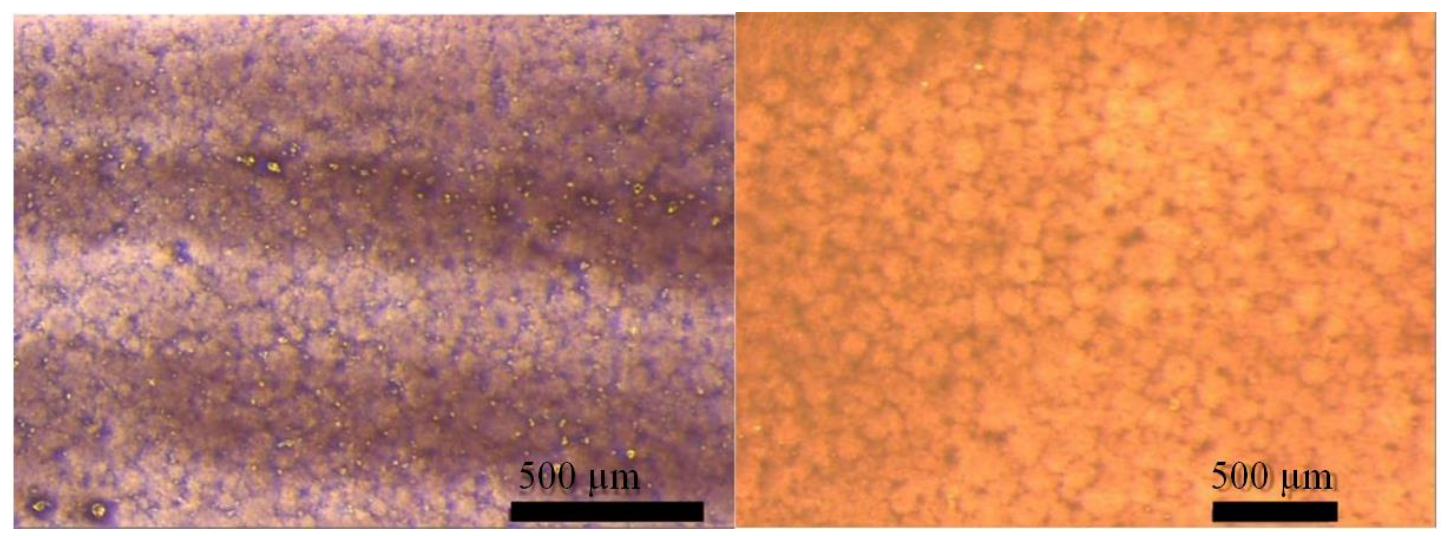

(a)

(b)

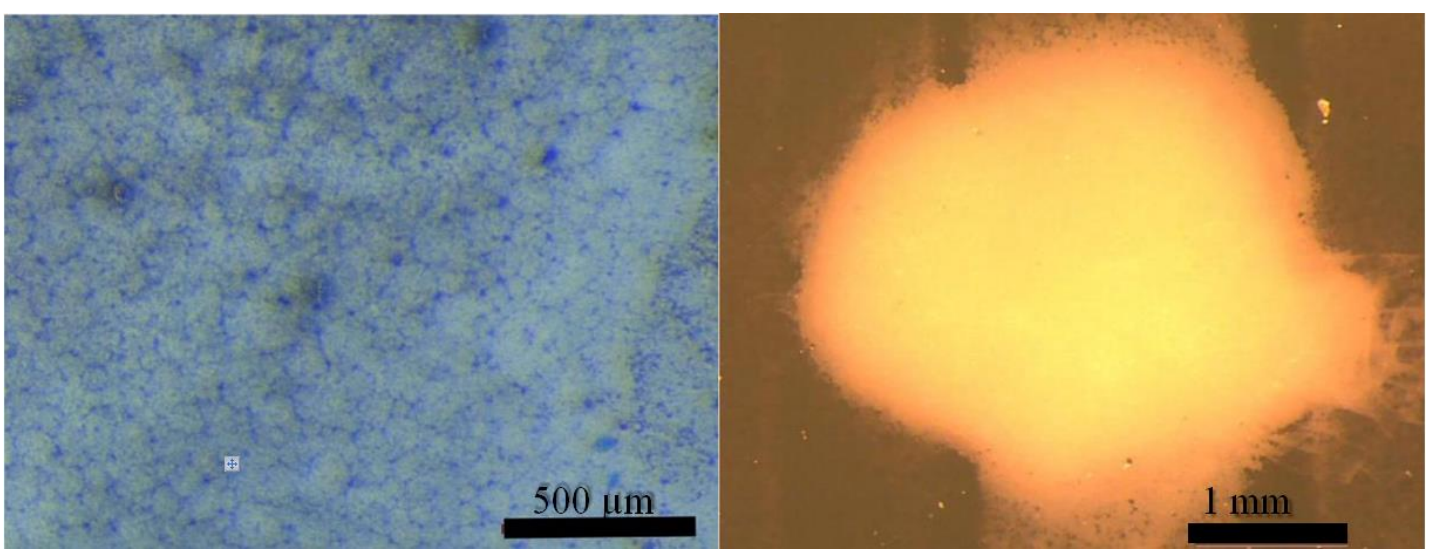

(b)

(d)

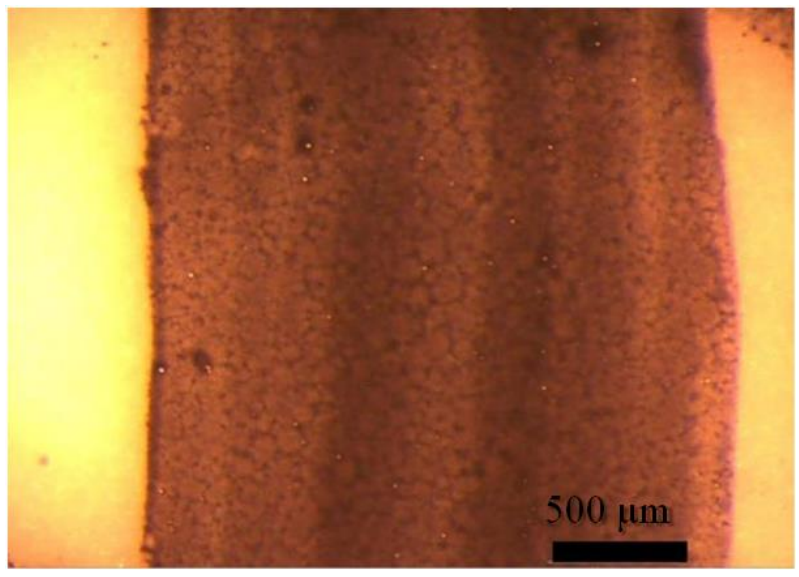

(e)

Figure 3 Optical images of crack-free surfaces of $\mathrm{Al}_{2} \mathrm{O}_{3}$ armour ceramics in both (a) and (b); and laser shock peened surfaces in (c), (d) and (e). 


\subsection{Micro-structural Modifications: Grain Boundary and Morphological Examination}

Figure 4(a) and (b) illustrates the processed micrographs of the of both the untreated and the laser shock peened surface areas of the $\mathrm{Al}_{2} \mathrm{O}_{3}$ armour ceramic plates which demonstrate the number of grain boundaries intercepting through specifically drawn lines on the micrographs. The values from the measurements are also shown in Table 3 and revealed that LSP begun to generate higher number of grain boundaries within the six specifically drawn lines over the surface on average (see Figure 4 (b)), as there were 168 grain boundaries passing through set of six lines that were in total $360 \mu \mathrm{m}$ long. This gave an average of $0.46 \mu \mathrm{m} \mathrm{AGI}$ as determined using equation 1. In comparison, the untreated surface comprised of $4 \%$ less grain boundaries, as the average grain boundaries over the area examined were 163 and gave an average of $0.45 \mu \mathrm{m}$. This was a good indication that a beginning of a prominent strengthening mechanism - grain boundary strengthening (applicable in poly-crystalline materials such as the one herein) was evident using the applied conditions presented in section 2.2. As such, the reduction in the grain size and higher number of grain boundaries per the specified area not only indicated smaller crystal structures (leading to the boost in hardness and fracture toughness as shown in latter sections), but also an increased probability of a dislocations becoming piled-up at the grain boundaries. With that said, a higher number of dislocations can be accommodated in the laser shock peened surfaces with lower grain sizes without allowing the material to flow. This leads to the need of higher number of dislocations density to begin yielding in the material, leading to higher strength. Thus, LSP showed a level of improvement that led to enhanced surface properties as presented further in this paper. It should be noted that the result, herein, comply with the Hall-Petch grain boundary strengthening theory [57]. As the grains reduce, the likelihood of dislocation motion into the grain boundary increases since the reduction in grain size had also minimized the distance between each grain. Therefore, an increase in the hardness by means of dislocation motion and most likely an effect of increased dislocation density occurred. Addition to this, it should also be noted that the Hall-Petch boundary grain boundary theory is also applicable to ceramic as well as metallic systems and has been reported by the work of Rothman et.al [58] and Trunec [59]. Beyond the scope of this paper, further studies addressing specifically the dynamics of the dislocation density are planned. 
Table 3 Interception of grains through scanning electron micrographs for both the untreated and the laser shock peened microstructure.

\begin{tabular}{|c|c|c|c|c|c|c|c|c|}
\hline \multirow{2}{*}{$\begin{array}{l}\text { Direct of } \\
\text { Measurement on } \\
\text { the micrograph }\end{array}$} & \multirow[b]{2}{*}{$\begin{array}{l}\text { Line } \\
(\mu \mathrm{m})\end{array}$} & \multirow[b]{2}{*}{ Length } & \multicolumn{3}{|c|}{ LSPned } & \multicolumn{3}{|c|}{ Untreated } \\
\hline & & & $\begin{array}{l}\text { No. of } \\
\text { Grains }\end{array}$ & Ave & $\begin{array}{l}\text { Grain } \\
\text { Size } \\
(\mu \mathrm{m})\end{array}$ & $\begin{array}{l}\text { No. of } \\
\text { grains }\end{array}$ & Ave & $\begin{array}{l}\text { Grain } \\
\text { Size } \\
(\mu \mathrm{m})\end{array}$ \\
\hline $\mathbf{Y}$ & & 60 & 29 & 0.483333 & 2.06 & 31 & 0.516667 & 1.93 \\
\hline $\mathbf{Y}$ & & 60 & 30 & 0.5 & 2 & 26 & 0.433333 & 2.30 \\
\hline $\mathbf{Y}$ & & 60 & 29 & 0.483333 & 2.06 & 29 & 0.483333 & 2.06 \\
\hline$X$ & & 60 & 29 & 0.483333 & 2.06 & 23 & 0.383333 & 2.06 \\
\hline $\mathbf{X}$ & & 60 & 25 & 0.416667 & 2.4 & 25 & 0.416667 & 2.4 \\
\hline $\mathbf{X}$ & & 60 & 26 & 0.433333 & 2.30 & 29 & 0.483333 & 2.06 \\
\hline Average & & 360 & 168 & 0.466667 & 2.15 & 163 & 0.452778 & 2.23 \\
\hline
\end{tabular}

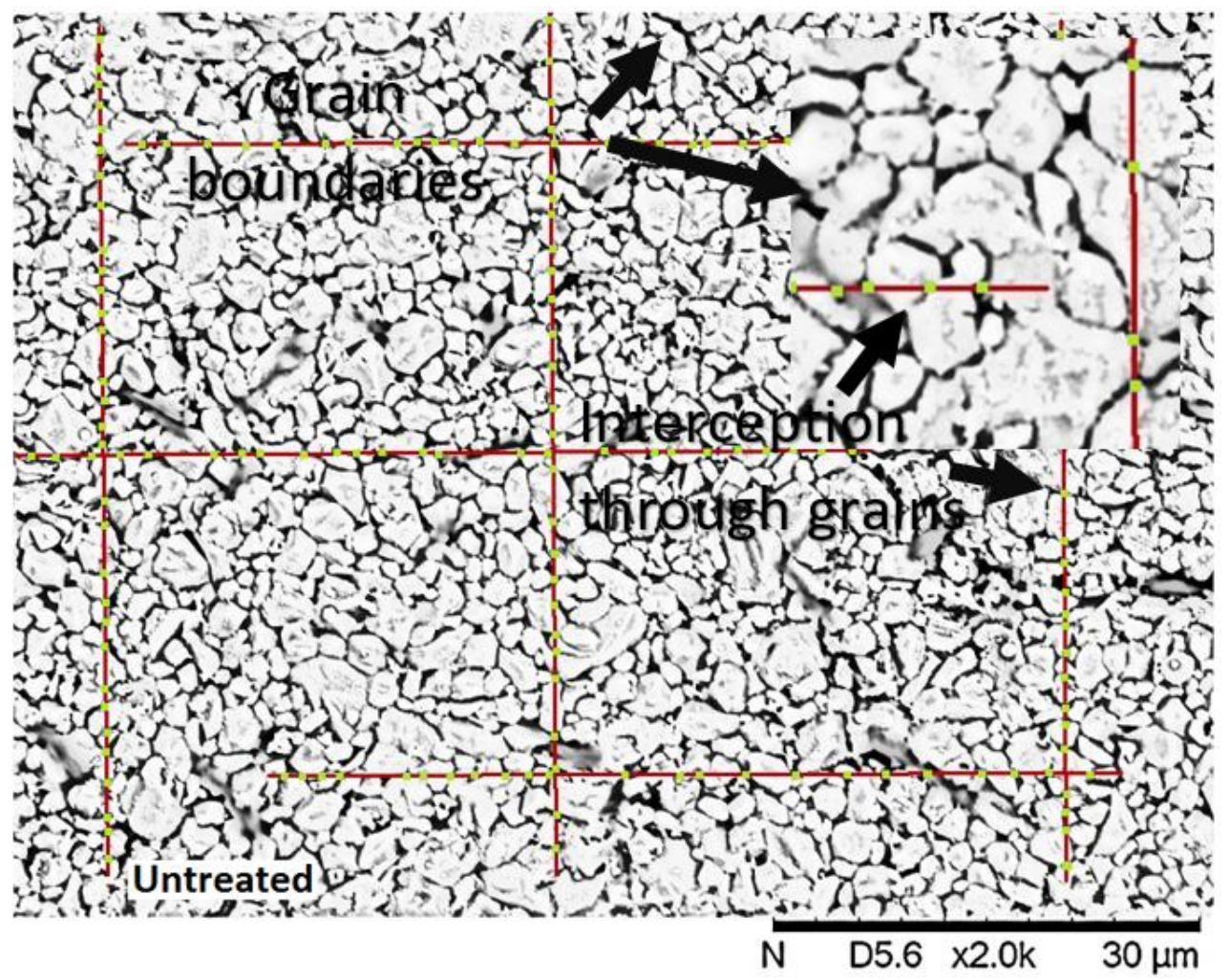

(a) 


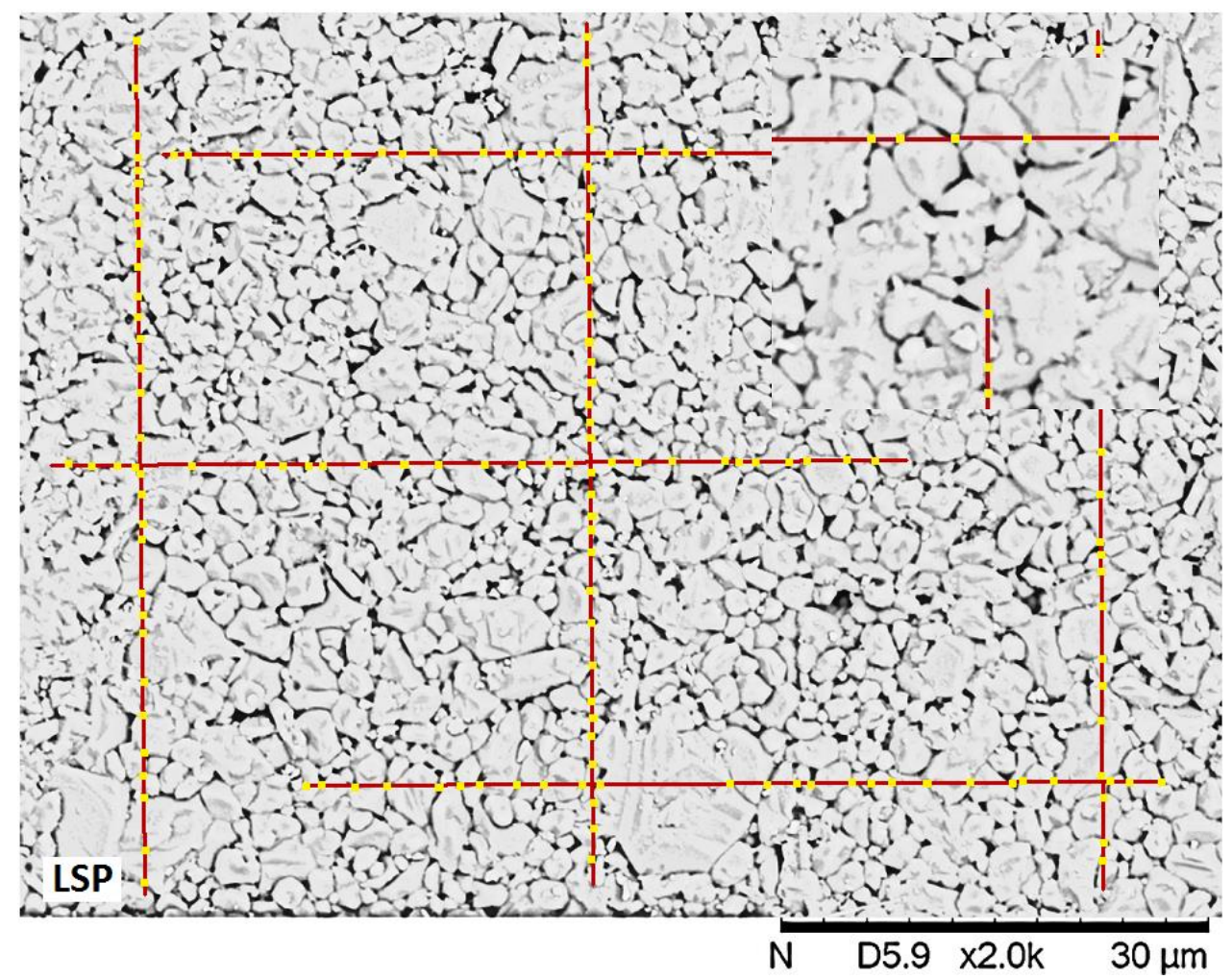

(b)

Figure 4 Processed SEM micrograph showing the granular structure and the grain intercept measurement of the untreated $\mathrm{Al}_{2} \mathrm{O}_{3}$ armour ceramics of (a), the untreated surface and (b), the laser shock peened surface.

Furthermore, both the low and high-resolution micrographs in Figure 5 showed that the laser shock peened surface demonstrated grain refinement of the microstructure, whilst the untreated surface comprised of initial defects (see Figure 5(a), (b), and (c) at $\times 1 \mathrm{~K}, \mathrm{x} 2 \mathrm{~K}$ and $\mathrm{x} 9 \mathrm{~K}$ resolution) that points towards pores, intergranular and intrinsic defects along with what appeared to be large spacing's between each grain and less compact when compared to the untreated $\mathrm{Al}_{2} \mathrm{O}_{3}$ armour ceramic. In other words, the grain boundaries were loosely attached with the untreated zones, and LSP (under the applied conditions (see section 2.2)) not only produced grain refinement, but also created a dense microstructure, resulting to an increased surface strength (and the mechanical properties examined in this study) with evidence of compacted grains (see Figure 5 (d), (e), (f) and (g)). Having said that, the LSP was undertaken using selected process parameters. As such, there was still the presence of pores and micro-voids, small cavities and canyons that remained with also some uncompact grains. This was so because, the full effect of the LSP surface treatment had not fully occurred, whereby, the pre-existing microstructural features hindering the strength would be considerably minimized and possibly eliminated. In order to make this successful would require a 
full parametric study of the $\mathrm{LSP} \mathrm{Al}_{2} \mathrm{O}_{3}$ armour ceramics, which in this case was beyond the scope of this paper.

One may postulate that different mechanism may exist for strengthening ceramics by LSP, however, a reduction in grain size and a refinement in the micro-structure is a common phenomenon with LSP of metallic materials. Previous work on LSP by Ahmed and Fitzpatrick [60], Milosavljevic et. al. [61], and Qiao et. al. [62], have demonstrated similar finding, whereby, microstructures were improved for marine steel, N-155 supper-alloy and TiAl respectively, and a reduction in the grains size of these metals was reported respectively. This has a similar effect to the one found in this work with the $\mathrm{Al}_{2} \mathrm{O}_{3}$ armour ceramics. It is also likely that metallic materials tend to transform from one phase to another. This has also been documented in previous investigations on laser peening without coating (LPwC) of AISI 321 steel by Karthik and Swaroop [63]. They suggested a transformation of austenite to martensite of $18 \%$ without any grain refinement. Rozmus et. al. [64] revealed that owing to the rapid cooling, after laser processing $\beta$ phase transformed to the $\alpha$-martensite phase within a Ti-6Al-4v was formed. Thus, any potential phase changes were measured to elucidate if phase transformation would have resulted after LSP of the $\mathrm{Al}_{2} \mathrm{O}_{3}$ armour ceramic. Figure 6 show an XRD spectra which demonstrated that the starting phase of the ceramic was $\alpha-\mathrm{Al}_{2} \mathrm{O}_{3}$ with corundum and did not alter after LSP, as no shift or broadening of the peaks were evident. Thus, a strong corundum phase was still present and was also evidenced in both the microstructures of the untreated and the laser shock peened surfaces of the $\mathrm{Al}_{2} \mathrm{O}_{3}$ armour ceramics. 


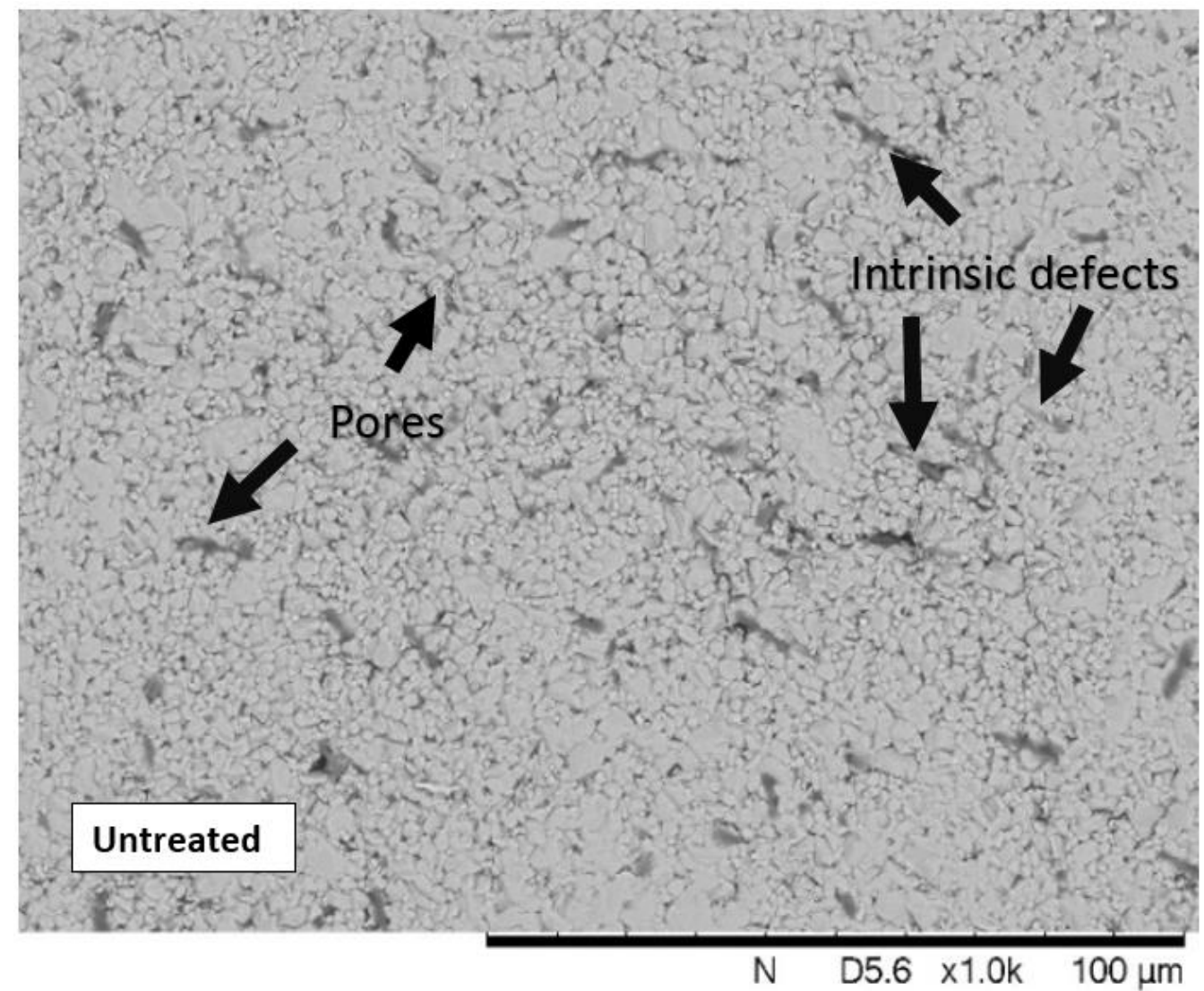

(a) the untreated $\mathrm{Al}_{2} \mathrm{O}_{3}$ armour ceramics at $\times 1 \mathrm{~K}$

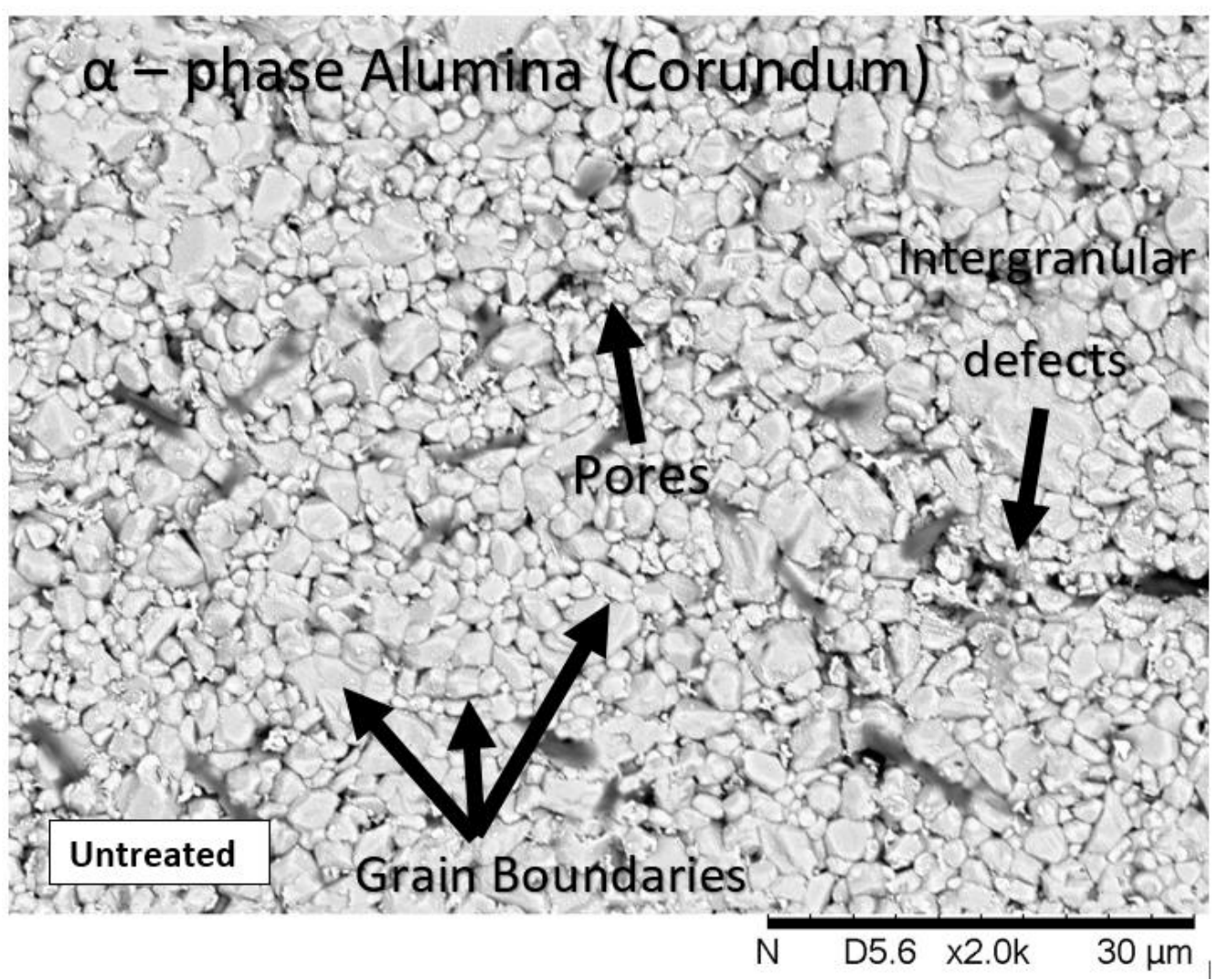

(b) the untreated $\mathrm{Al}_{2} \mathrm{O}_{3}$ armour ceramic at $x 2 \mathrm{~K}$ resolution 


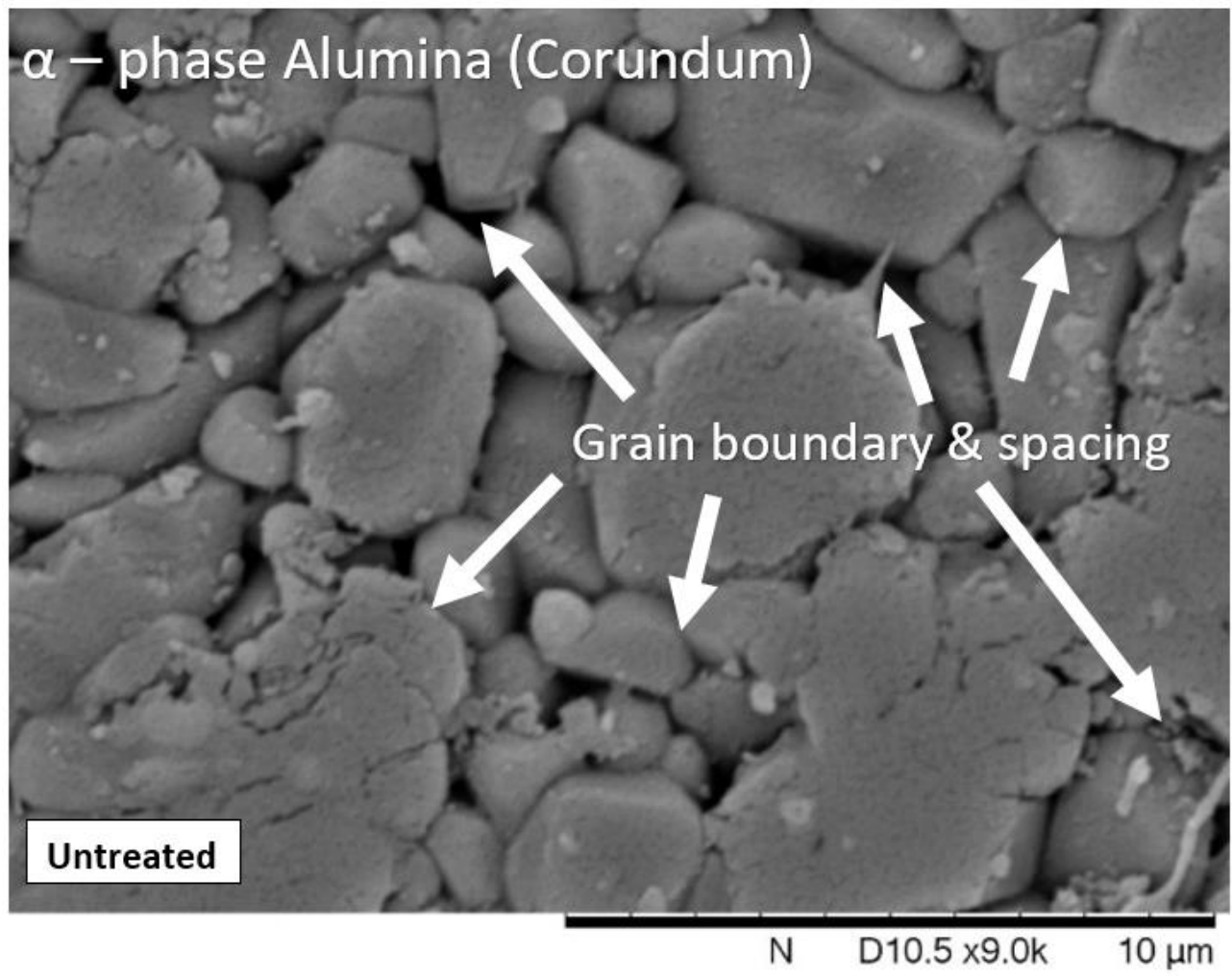

(c) the untreated $\mathrm{Al}_{2} \mathrm{O}_{3}$ armour ceramic at $\times 9 \mathrm{~K}$ resolution

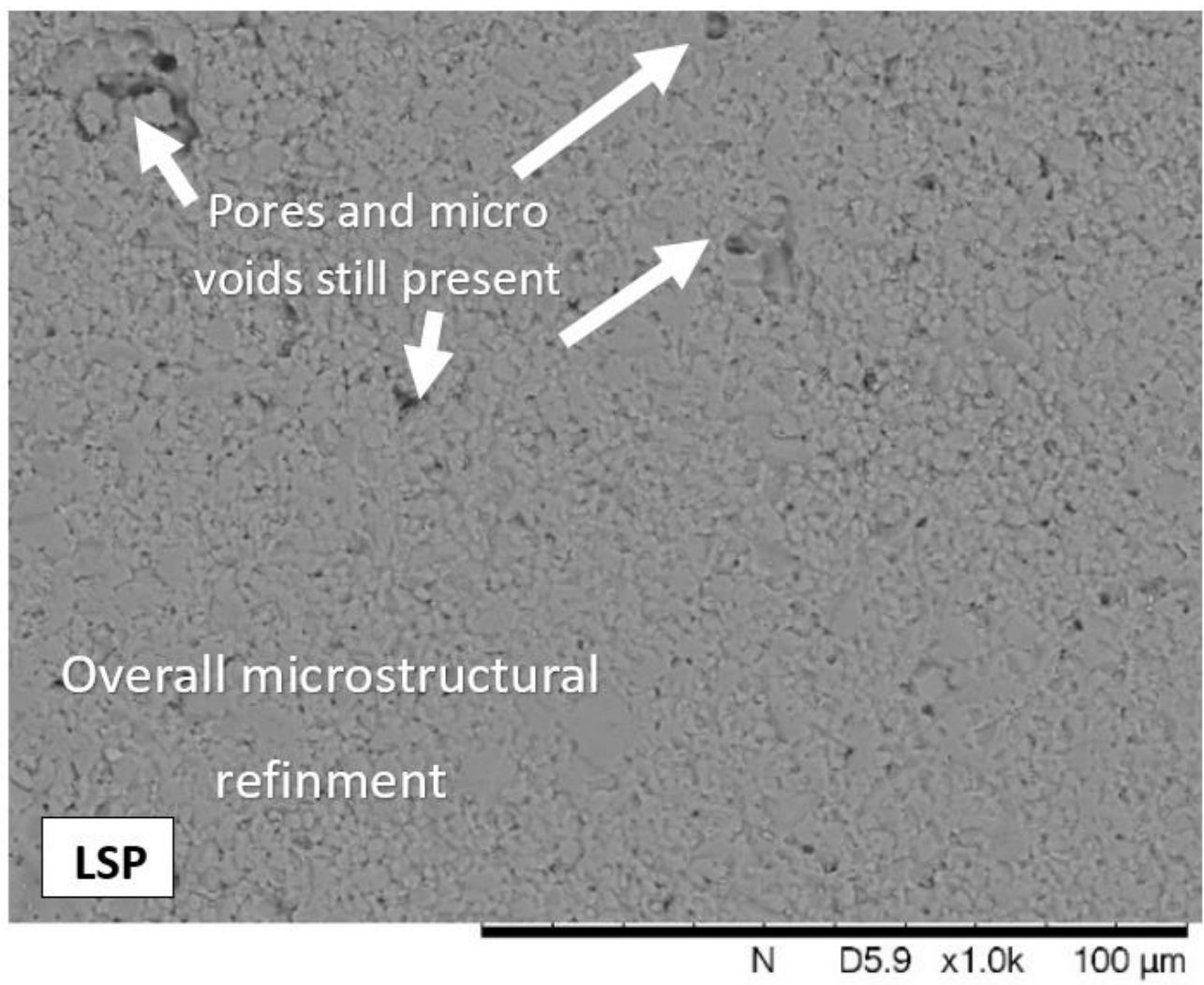

(d) laser shock peened $\mathrm{Al}_{2} \mathrm{O}_{3}$ armour ceramic at $x 1 \mathrm{k}$ resolution 


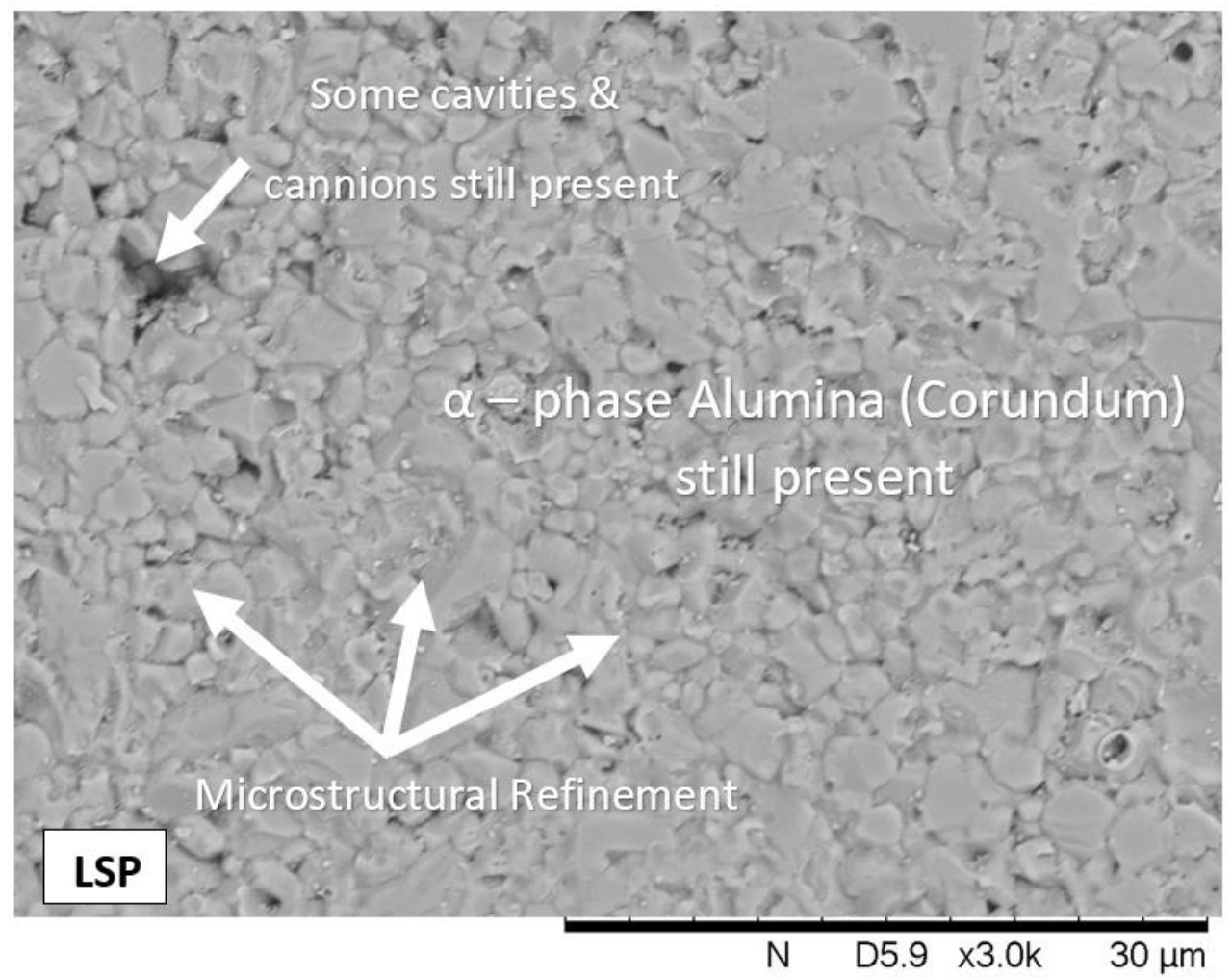

(e) laser shock peened $\mathrm{Al}_{2} \mathrm{O}_{3}$ armour ceramic at $\times 3 \mathrm{~K}$ resolution

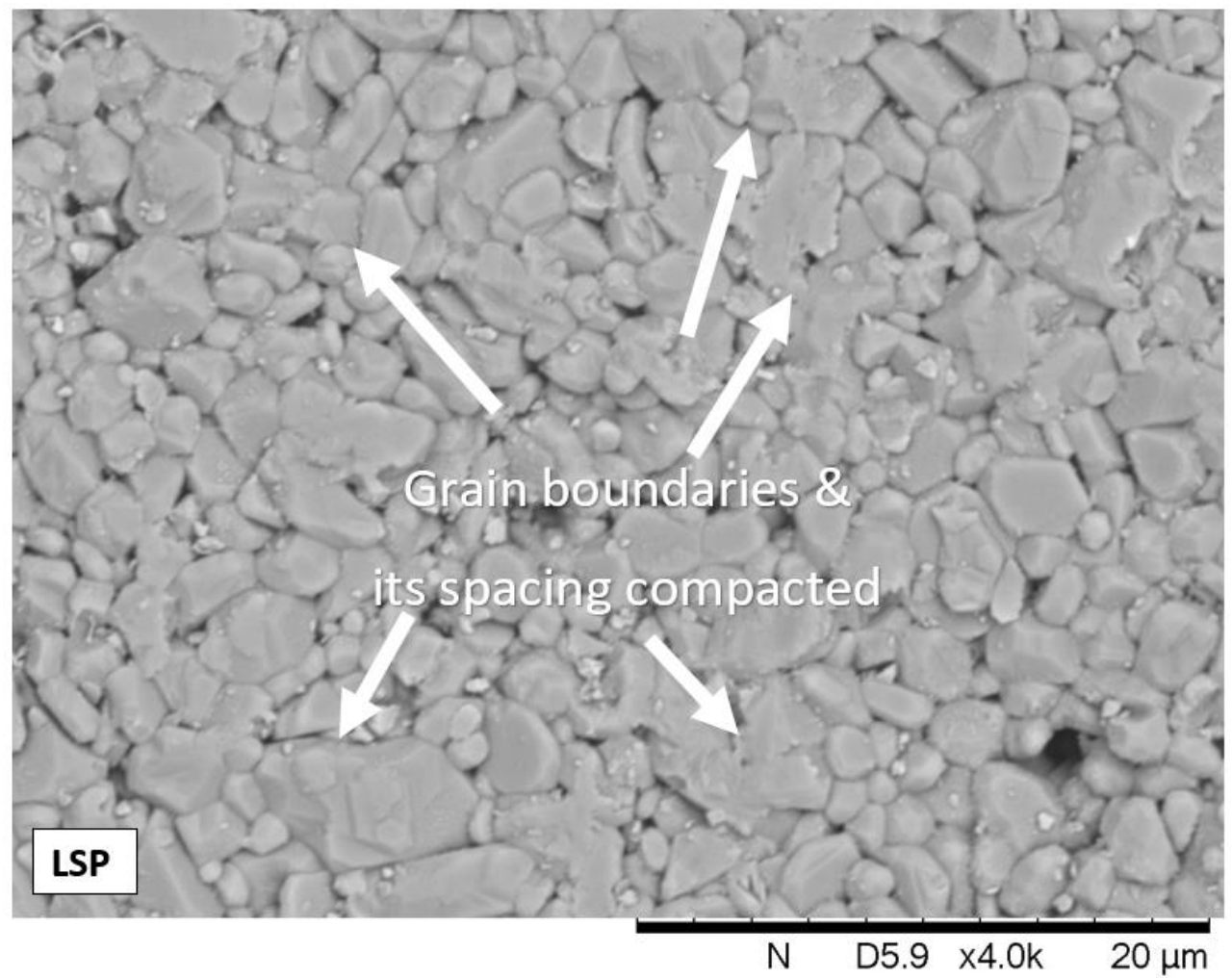

(f) laser shock peened $\mathrm{Al}_{2} \mathrm{O}_{3}$ armour ceramic at $\times 4 \mathrm{~K}$ resolution 


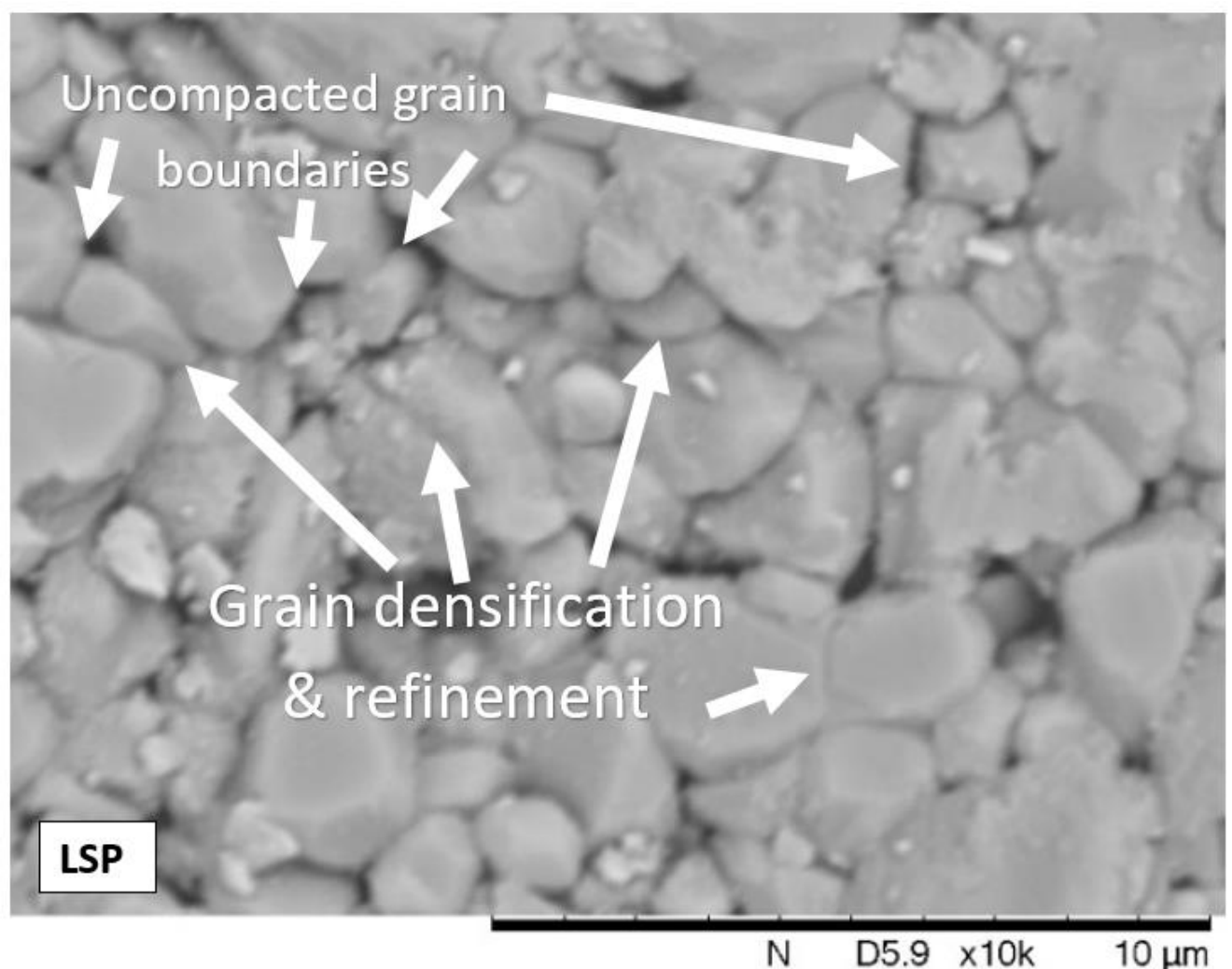

(g) laser shock peened $\mathrm{Al}_{2} \mathrm{O}_{3}$ ceramic at $\times 10 \mathrm{~K}$ resolution

Figure 5 SEM images of the untreated and laser shock peened microstructures of the $\mathrm{Al}_{2} \mathrm{O}_{3}$ ceramic armour plates in (a) to $(\mathrm{g})$ at $1 \mathrm{~K}$ to $10 \mathrm{~K}$ resolution. 


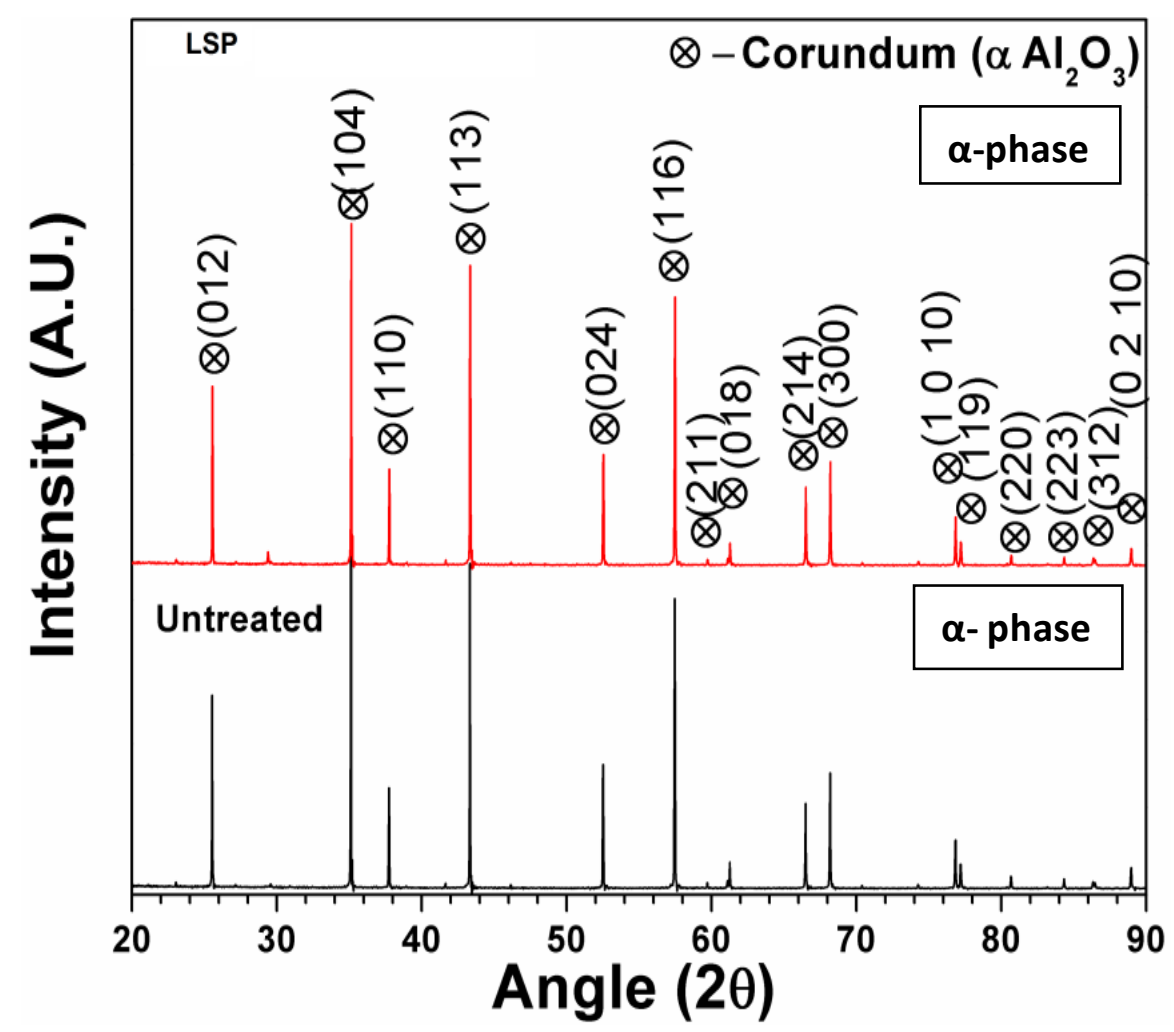

Figure 6 Phase distribution of the $\mathrm{Al}_{2} \mathrm{O}_{3}$ armour ceramics for both the untreated and Laser shock Peened surfaces showing unchanged a-corundum phase.

\subsection{Surface Roughness}

The surface roughness and related parameters were measured for both the untreated and the laser shock peened $\mathrm{Al}_{2} \mathrm{O}_{3}$ armour ceramics as presented in Table 4 with both the 2-D and 3-D profiles also shown in Figure 7(a), (b), (c) and (d) for the untreated surfaces and Figure 8 (a), (b, (c) and (d) for the laser shock peened surface. Unlike the dimpling effects that are conventionally reported with metallic materials, the dimpling effects does not particularly occur with ceramics due to firstly, the nature of the material being already hard, brittle and significantly high stiffness. Secondly, the low laser energy applied during LSP, despite applying 5 pulses was not high enough to create a large amount of shock pulse pressure to generate the dimpling effect. Regards to surface roughness, the arithmetic mean deviation of the roughness profile Ra was measured to be $0.56 \mu \mathrm{m}$ for the untreated surface, whilst the laser shock peened surface was measured to be $0.91 \mu \mathrm{m}$. This was an increase in roughness by just over $61 \%$. The Rv parameter (maximum valley depth of the roughness profile) started out as $2.55 \mu \mathrm{m}$ for the untreated surface and after LSP increased to an average of $4.23 \mu \mathrm{m}$ - an increase of $66 \%$ after LSP. Obviously, with increasing the laser impacts would have resulted to enough ablation of the material, whereby, deeper valleys would be created. The maximum average height of the roughness profiles $(\mathrm{Rz})$ was measured to be $4.26 \mu \mathrm{m}$ for the untreated surface, whilst, the height increased to $6.56 \mu \mathrm{m}$ post LSP of the $\mathrm{Al}_{2} \mathrm{O}_{3}$ armour ceramic 
which was a $54 \%$ increase after LSP. It is highly likely that if the troths became deeper, then the respective kinks were also increasing which was overall increasing the roughness of the laser shock peened surfaces. Likewise, the "S" parameters presented in Table 4 had also increased and showed similar trend as to the "Ra" values. A comparison of the untreated surfaces with the laser shock peened surfaces confirmed the conventional effects that generally occur during LSP of metals also resulted during LSP the $\mathrm{Al}_{2} \mathrm{O}_{3}$ armour ceramics. It is evident that due to the interaction of the laser beam with $\mathrm{Al}_{2} \mathrm{O}_{3}$ armour ceramic with multiple impacts applied in this work, would have resulted to some ablation, leading to material removal which increased the surface roughness and resulted to a courser surface as expected.

Usually with LSP of metallic materials, it is conventionally reported that surface roughness increases [65], particularly, with multiple overlapping impacts (100\% overlap with 5 impacts in this case). Indeed, the surface roughness is dependent on the condition of the initial starting surface, but the general phenomenon in relation to LSP is that the absorption of the laser into the absorptive layer is generally uneven on a flat sample substrate [65]. Due to attenuation, there will be a difference in intensity as the laser shock propagates into the air between the $\mathrm{Al}_{2} \mathrm{O}_{3}$ and the ink ablative layer [65]. This inherently will produce a difference in shockwave at different positions and create a rougher surface. Having said this, there is certainly a benefit of producing a rougher surface for the ballistic application. This is because benefits of roughening the surface of a ballistic plate would produce a courser surface that could modify the wetting characteristic, thus, improve the contact angle during its contact with the polymer based adhesive. This inherently would not only improve the bond strength during its assembly with the Kevlar ${ }^{\mathrm{TM}}$ backing layer, but in turn, would also increase the impact resistance as the ceramic side plates would deem stronger due to a dense surface packaging. 
Table 4 Examined Surface Roughness Parameters of the untreated and the laser shock peened $\mathrm{Al}_{2} \mathrm{O}_{3}$ Armour Ceramic.

\begin{tabular}{|c|c|c|c|c|c|c|}
\hline \multirow{2}{*}{$\begin{array}{c}\text { Surface } \\
\text { finish } \\
\text { Parameters }\end{array}$} & \multicolumn{3}{|c|}{ Untreated } & \multicolumn{3}{|c|}{ LSPned } \\
\hline & Ave $(\mu \mathrm{m})$ & $\begin{array}{l}\text { Range ( } \mu m) \\
\text { Max - Min }\end{array}$ & $\begin{array}{l}\text { STVD } \\
(\mu \mathrm{m})\end{array}$ & Ave ( $\mu \mathrm{m})$ & $\begin{array}{c}\text { Range ( } \mu \mathrm{m}) \\
\text { Max-Min }\end{array}$ & $\begin{array}{l}\text { STVD } \\
(\mu \mathrm{m})\end{array}$ \\
\hline Ra & 0.5694 & $0.664-0.485$ & 0.076553 & 0.9138 & $0.944-0.885$ & 0.022709 \\
\hline Rv & 2.554 & $2.75-2.01$ & 0.316275 & 4.23 & $4.9-3.99$ & 0.377955 \\
\hline $\mathbf{R q}$ & 0.7296 & $0.847-0.599$ & 0.109475 & 1.16 & $1.5-1.15$ & 0.172105 \\
\hline Rsk & -0.406 & $(-0.345)-(-0.487)$ & 0.061806 & -0.55288 & $(-0.5052)-(-0.595)$ & 0.036778 \\
\hline $\mathbf{R z}$ & 4.266 & $4.99-3.75$ & 0.496216 & 6.562 & $7.08-6.05$ & 0.385966 \\
\hline Sa & 4.546 & $4.71-4.21$ & 0.198066 & 4.898 & $5.19-4.38$ & 0.306219 \\
\hline Sz & 306.2 & $309-304$ & 2.167948 & 398 & $402-395$ & 2.54951 \\
\hline Sv & 289.4 & 294- 286 & 2.880972 & 377.4 & $382-374$ & 3.130495 \\
\hline $\mathrm{Sq}$ & 6.54 & $6.91-6.19$ & 0.283725 & 6.304 & $6.59-6.02$ & 0.240687 \\
\hline Sp & 15.4 & $16.3-14.4$ & 0.860233 & 19.82 & $21.9-18.5$ & 1.413153 \\
\hline
\end{tabular}

X Profile: $\Delta X=1.1811 \mathrm{~mm} ; \Delta Z=-0.4084 \mu \mathrm{m}$

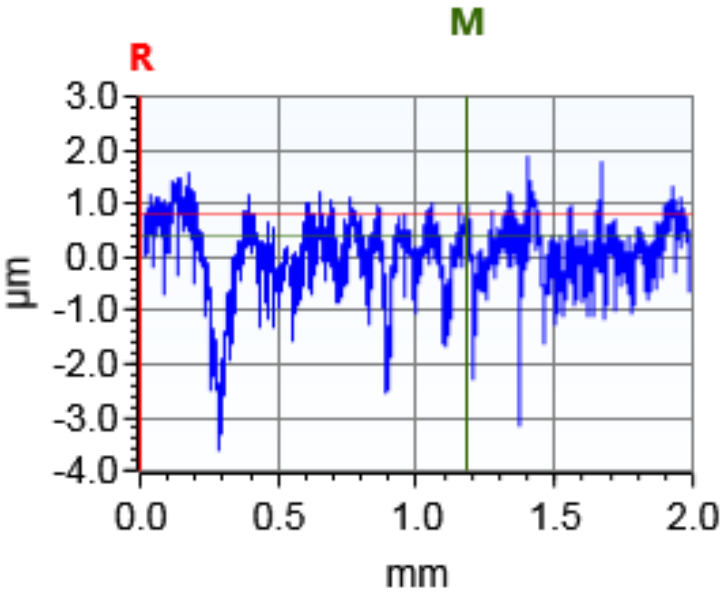

(a)
Y Profile: $\Delta \mathrm{X}=1.0588 \mathrm{~mm} ; \Delta \mathrm{Z}=0.2644 \mu \mathrm{m}$

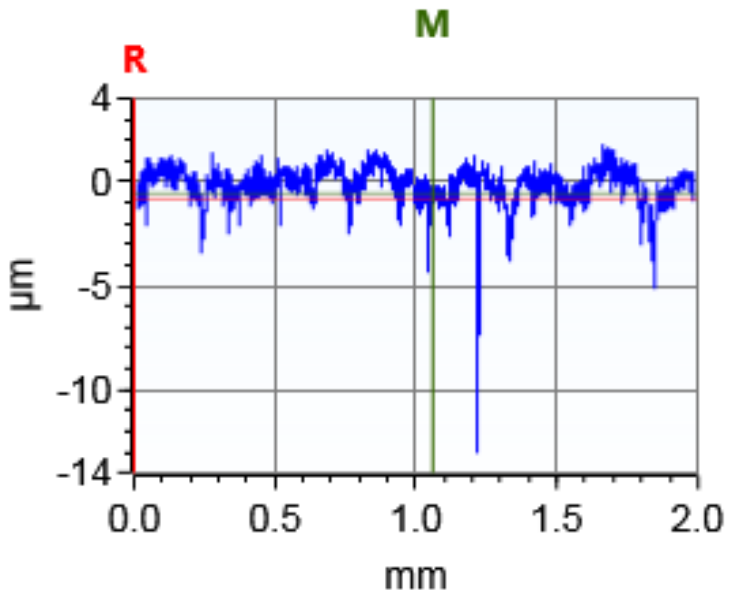

(b) 


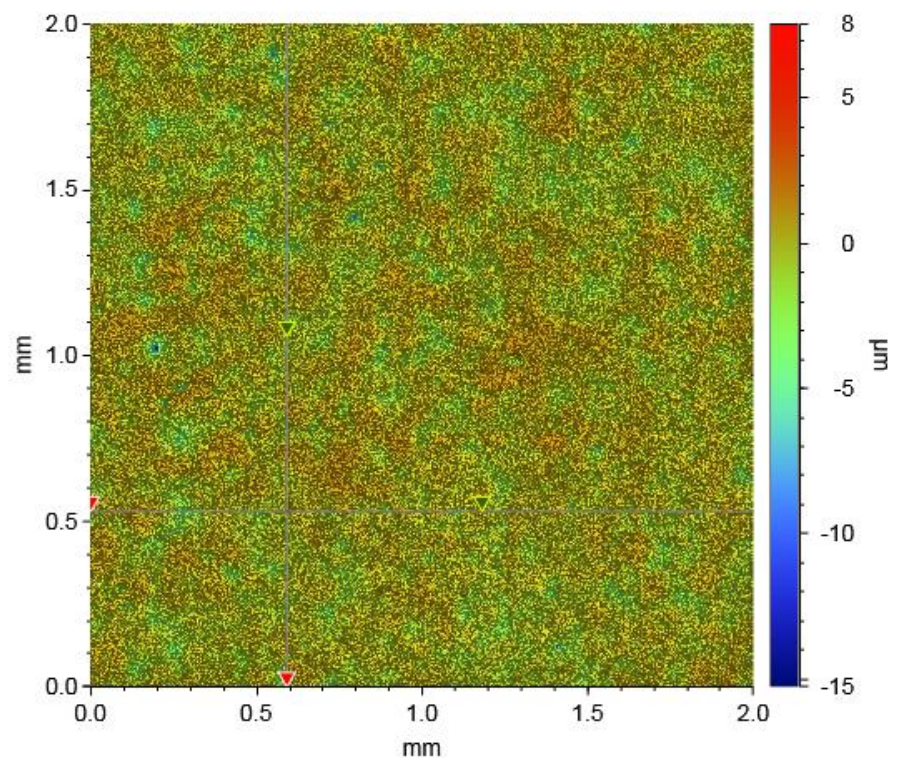

(c)

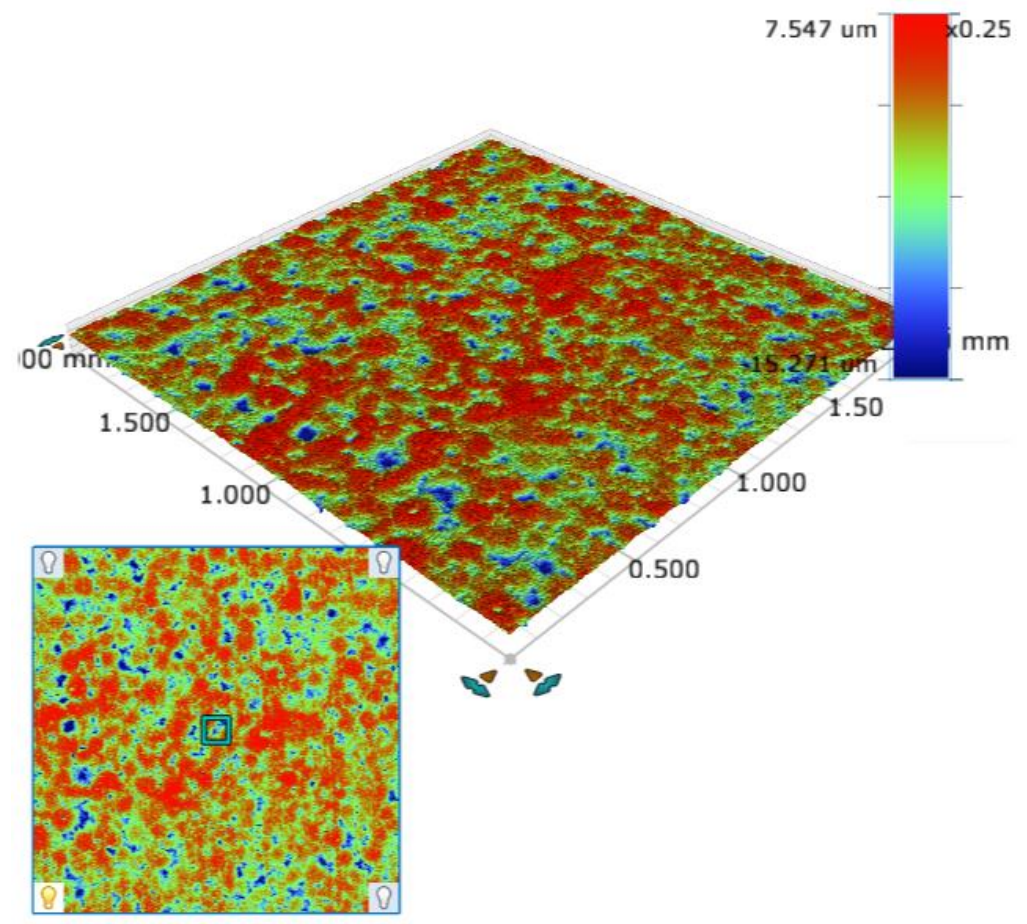

(d)

Figure 72-D Topography of the untreated $\mathrm{Al}_{2} \mathrm{O}_{3}$ armour ceramics in (a) and (b), a 2-D surface map in (c); and (d) a 3-D profile of the untreated Alumina Armour Ceramic. 


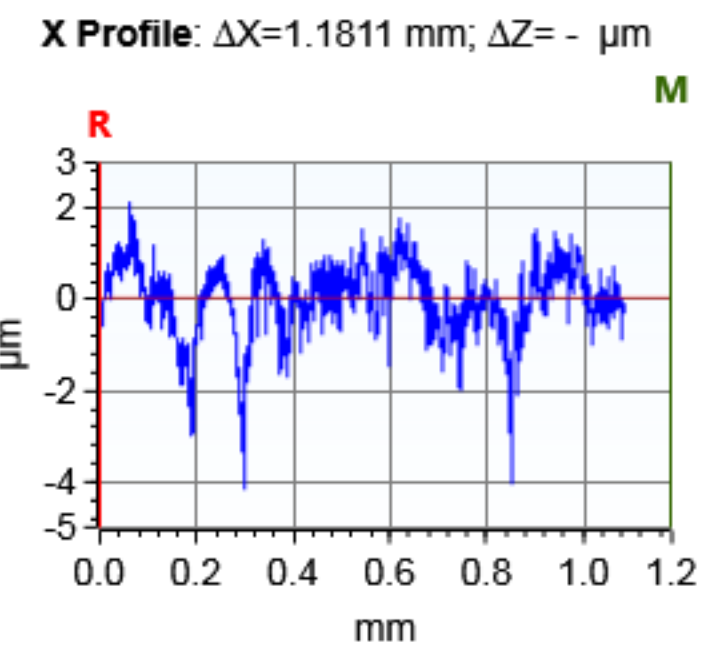

(a)
Y Profile: $\Delta X=1.0588 \mathrm{~mm} ; \Delta \mathrm{Z}=1.5993 \mu \mathrm{m}$

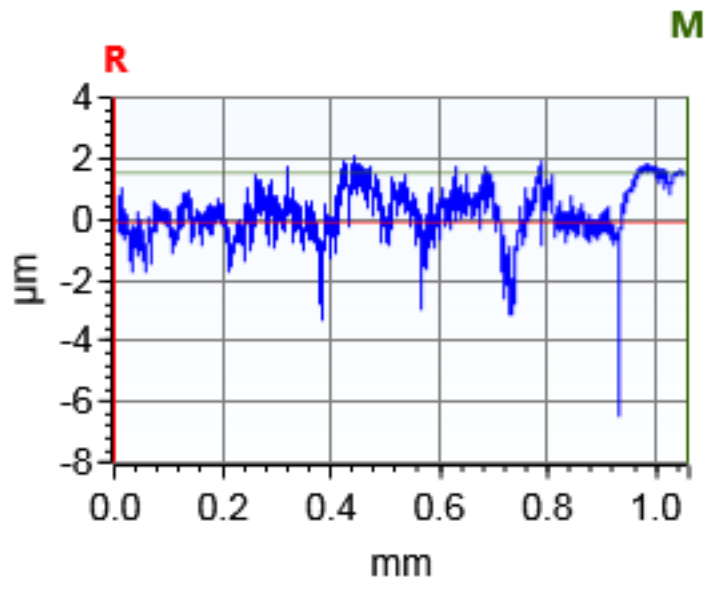

(b)

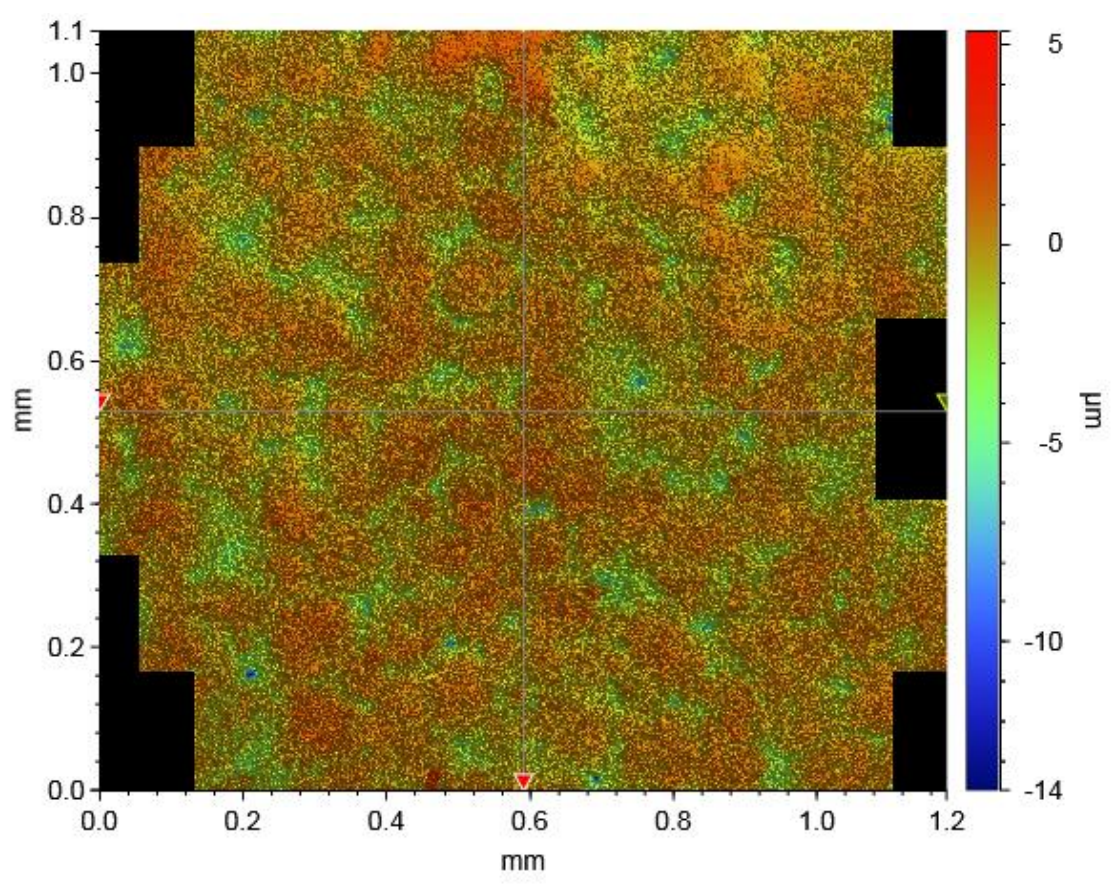

(c) 


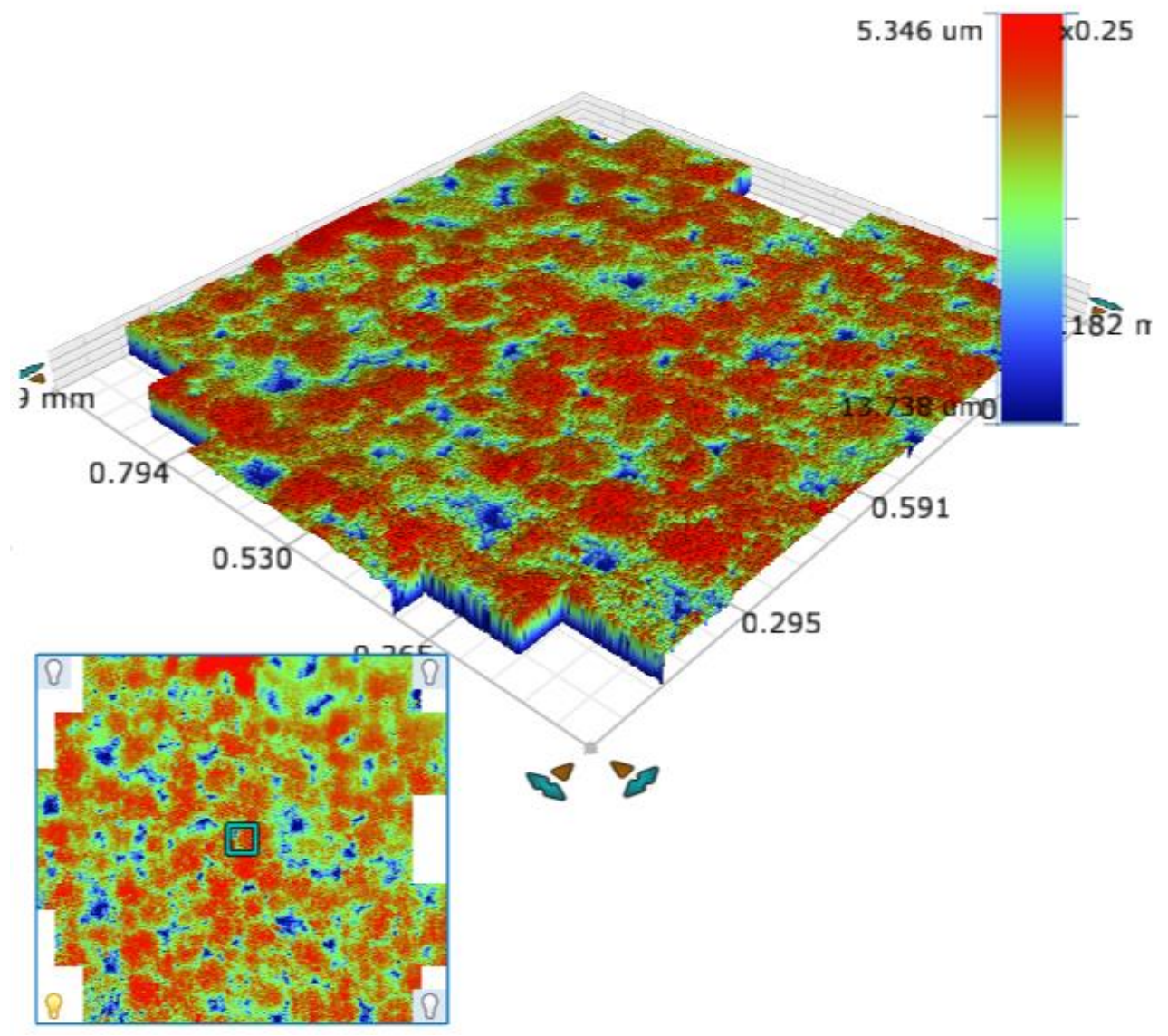

(d)

Figure 8 Topography of the untreated $\mathrm{Al}_{2} \mathrm{O}_{3}$ armour ceramics in (a) and (b), a 2-3 surface map in (c); and (d) a 3-D profile of the laser shock peened Alumina Armour Ceramic.

\subsection{Modification in Hardness}

The change in hardness between the untreated and the laser shock peened $\mathrm{Al}_{2} \mathrm{O}_{3}$ armour ceramics is presented in Figure 9 and the graph in Figure 10. The hardness measured of over the untreated surface was $1009 \mathrm{HV}$ from an average of 10 indentation tests which was conducted at a spacing of 5 indentations footprints [66]. A best attempt was made to place a single indentation at the centre of the spot, although, it is possible that all ten indentations were slightly off the centre which could be noted for future study for improvement. The highest value from the mean was $1075 \mathrm{HV}$, whilst the lowest from the mean was 950HV. In comparison, the average hardness of the laser shock peened area was $1118 \mathrm{HV}$, whilst the highest was $1240 \mathrm{HV}$ and the lowest being 995HV. Comparatively, the increase in hardness was $10 \%$ after LSP surface treatment. A change in hardness of $\pm 10 \%$ is usually expected with ceramic materials as stated in previous literature [46]. However, it is believed that the granular structure of a fine-grain ceramic for ballistic application is usually uniform and therefore, should not deviate to that extent which indicate and confirm the 
boost in hardness as result of the LSP for the $\mathrm{Al}_{2} \mathrm{O}_{3}$ armour ceramic used herein. Regards to the deviation of hardness from the mean for the untreated $\mathrm{Al}_{2} \mathrm{O}_{3}$ ceramic armour plate, a maximum of $7 \%$ was present, whilst the deviation from mean for the laser shock peened surface was $11 \%$. This goes to show that despite ceramics being hard and brittle, there was an improvement in the surface integrity. At the same time, the hardness enhancement may have increased the brittleness of the material. The mechanism behind the change in hardness was therefore attributed to firstly a microstructural refinement which was evident from the SEM images as well as grain refinement that was observed from the micrographs in Figure $5(\mathrm{~d})$ to $(\mathrm{g})$.

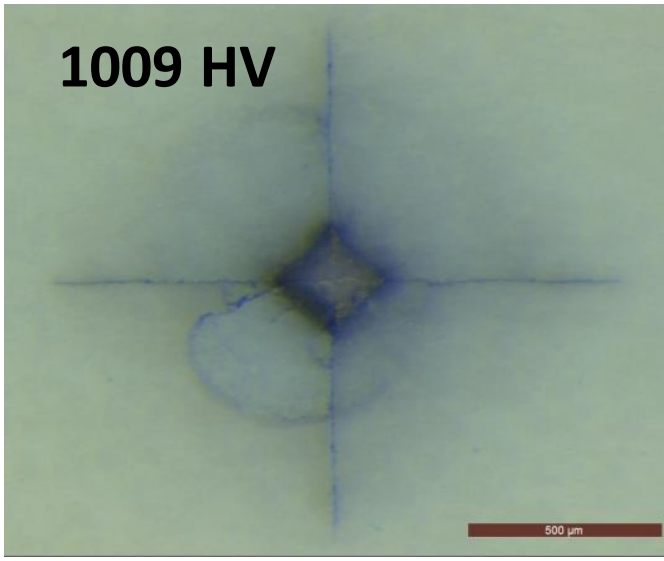

(a)

\section{HV}

(b)

Figure 9 An example of an indentation replica for the untreated zones in (a) and the laser shock peened zone of the $\mathrm{Al}_{2} \mathrm{O}_{3}$ armour ceramic in (b).

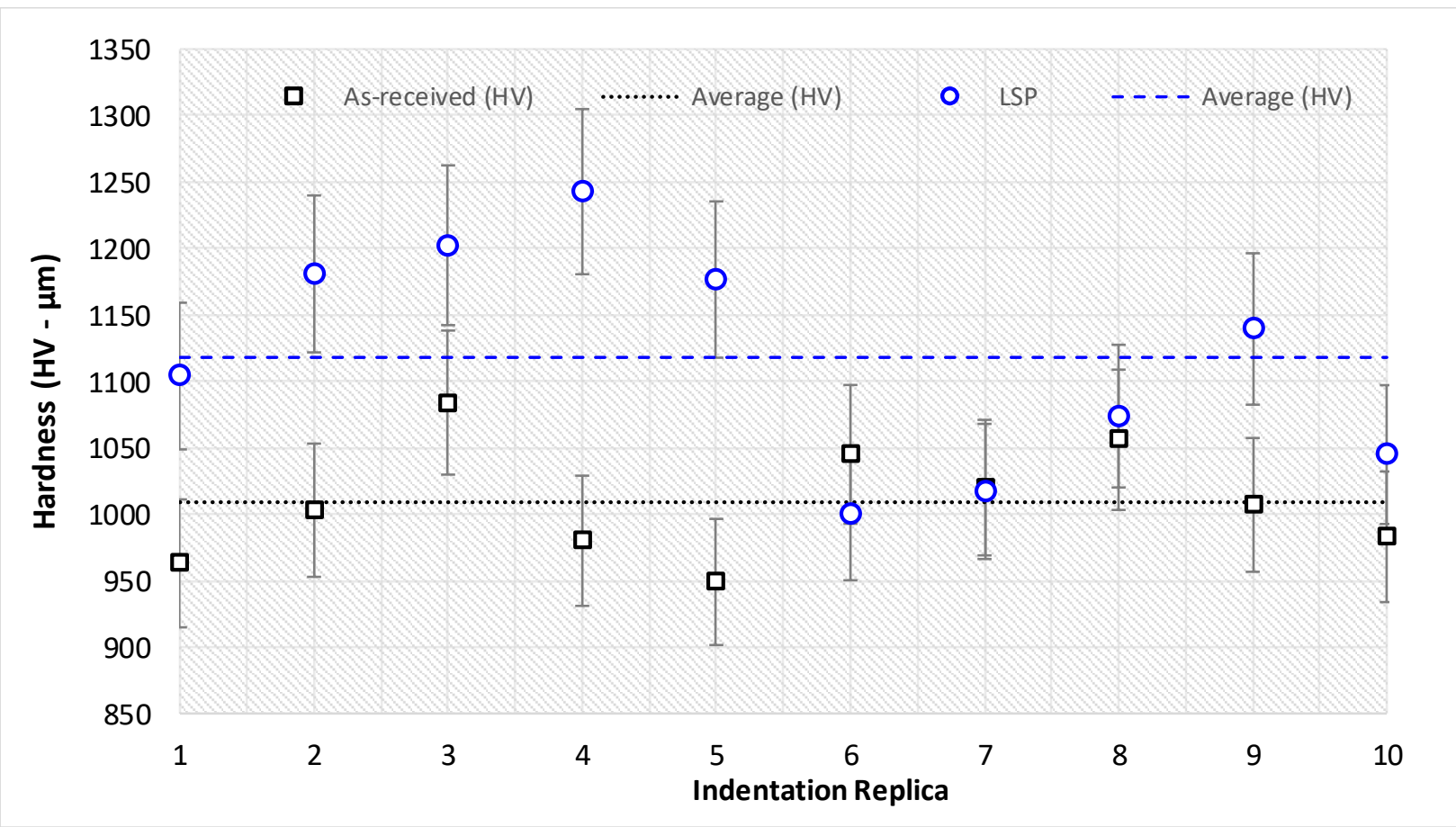




\section{Figure 10 Modification in hardness of the untreated and the laser shock peened $\mathrm{Al}_{2} \mathrm{O}_{3}$}

armour ceramic.

\subsection{Changes in Indentation Size}

Figure 11 (a) and (b) shows an optical image of one of the example of the indentation footprints for both the untreated and laser shock peened surfaces. Figure 12 is a graphical representation of the change in the indentation size over ten indentation replicas of the untreated and treated surface. The average indentation size was $300 \mu \mathrm{m}$ with a highest reading of $310 \mu \mathrm{m}$ and the lowest being $290 \mu \mathrm{m}$. In comparison, the laser shock peened surface yielded an average indentation size of $285 \mu \mathrm{m}$ with a highest indentation size of $304 \mu \mathrm{m}$ and a lowest being $271 \mu \mathrm{m}$ from the mean. The difference between the two surfaces was $5 \%$ as the laser shock peened surface showed a decrease in the indentation foot-print which confirms the enhancement in hardness of $11 \%$ as shown in the previous section. Generally, as the hardness increases, the material would become brittle as ductility would inherently reduce. Having said that, the laser shock peened surface showed better response to diamond indentations despite the boost in the hardness. This was indicating that the laser shock peened surface showed more resistance to mechanical impact. This effect could be attributed to both the micro-structural refinement from the untreated surface of the $\mathrm{Al}_{2} \mathrm{O}_{3}$ ceramic armour plates. In addition, an increase in the residual compressive stress would also have led to this cause as demonstrated further in this study. The fluctuation of the indentation size of the diamond foot-print was about 3\% for the untreated surface and about $6 \%$ for the laser shock peened surface. This goes to show that there was more variation in the results of the laser shock peened area. This is expected as the surface was considerably modified and may contain inhomogeneous areas of LSP that varied in strength at localised level within the ceramic and its substructure.

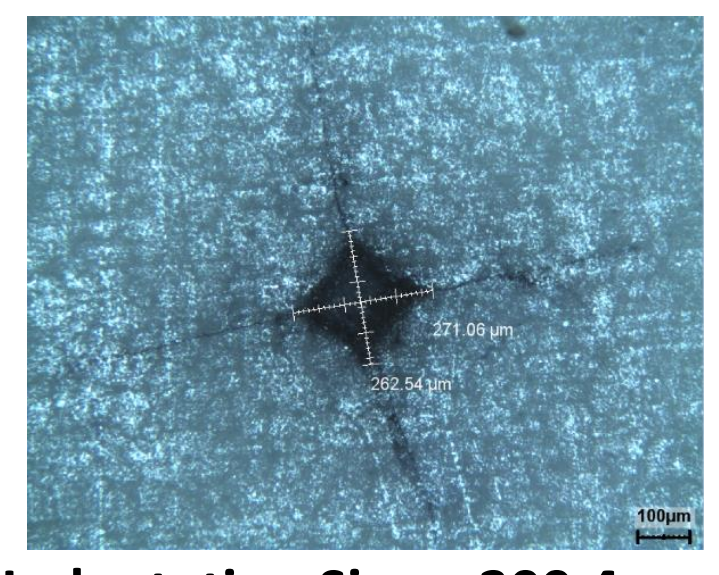

Indentation Size $=\mathbf{3 0 0 . 4} \boldsymbol{\mu m}$

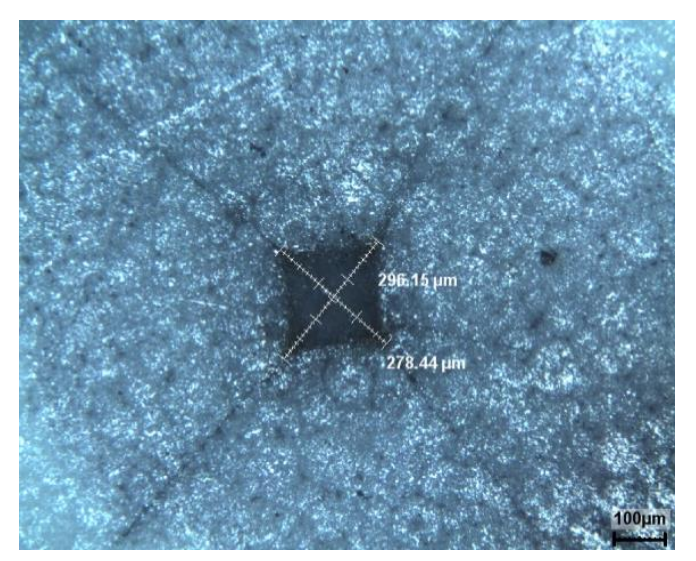

Indentation Size $=\mathbf{2 8 5 . 7} \mu \mathrm{m}$

(a)

(b) 
Figure 11 An example of the Vickers indentation replica comparing the change in indention size of the untreated surface in (a) and the laser shock peened surface in (b) of the $\mathrm{Al}_{2} \mathrm{O}_{3}$ armour ceramic.

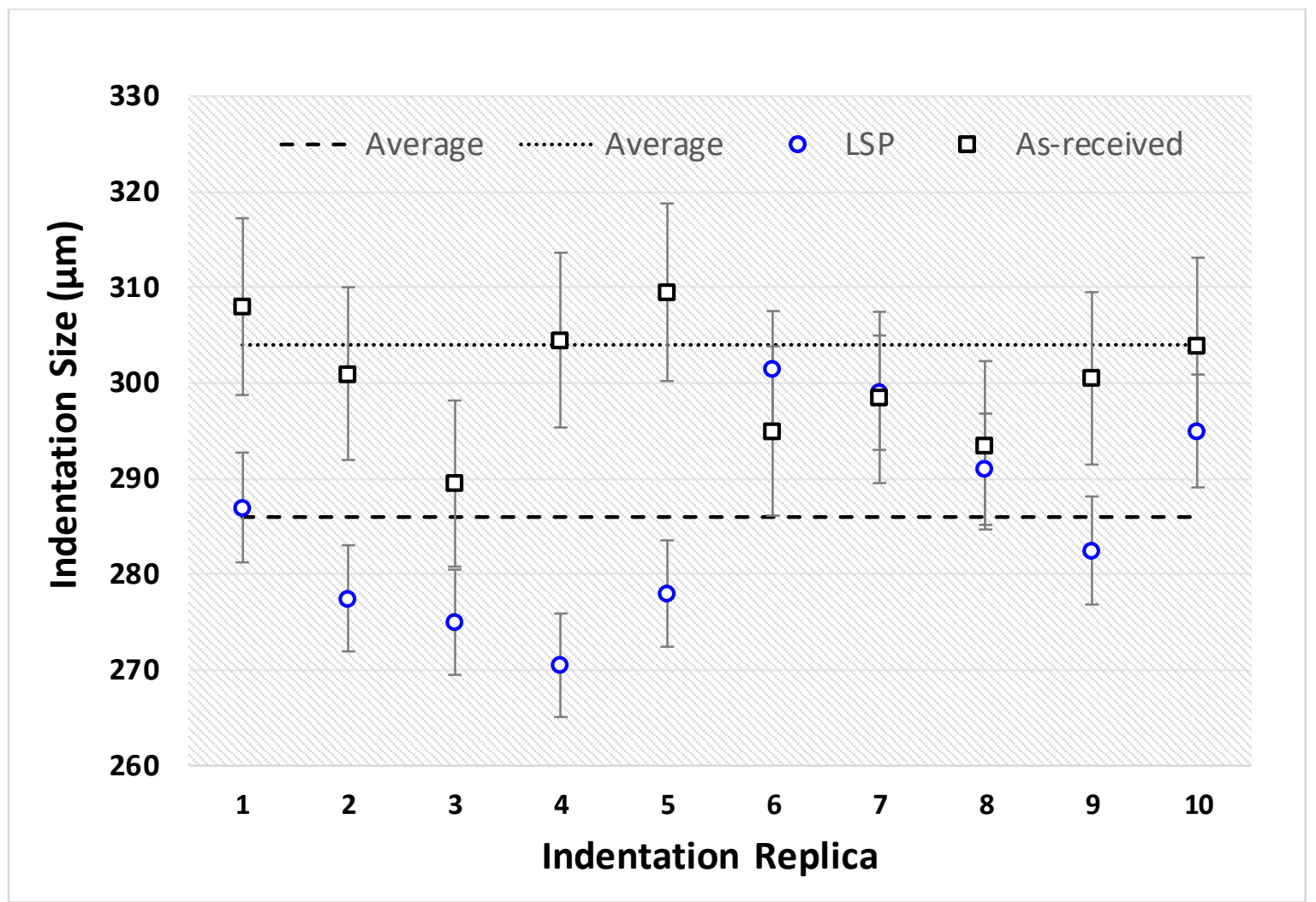

Figure 12 Examination of the indentation size for both the untreated and the laser shock peened $\mathrm{Al}_{2} \mathrm{O}_{3}$ armour Ceramics.

\subsection{Evaluation of Crack Lengths}

Figure 13 is a comparison between the flaw size of both the untreated and the laser shock peened surface and Figure 14 represents the modification of crack lengths for both the untreated and the laser shock peened surfaces of the $\mathrm{Al}_{2} \mathrm{O}_{3}$ ceramic armour plate. A difference in flaw size between the two surfaces was $10.5 \%$, as the untreated surface testified an average crack length of $1163 \mu \mathrm{m}$. The highest crack length above the mean value was $1375 \mu \mathrm{m}$ and the lowest was $1035 \mu \mathrm{m}$. At the same time, the laser shock peened surface exhibited a mean crack length value of $1040 \mu \mathrm{m}$ with a $1050 \mu \mathrm{m}$ as the lowest and the highest being $1150 \mu \mathrm{m}$. The crack lengths of the untreated $\mathrm{Al}_{2} \mathrm{O}_{3}$ armour ceramic fluctuated from the mean by a maximum of $18 \%$. This is considerable and indicated that the surface comprised of pre-existing micro-cracks and surface defects. As a comparison, the cracks exhibited by the laser shock peened surface were evenly distributed and did not deviate to a great extent from the mean (4\%). This indicated that the surface had better indentation response 
and provided some shielding against the indentation force exerted by the Vickers diamond indentation. It is generally expected that with increase in the brittleness of the ceramic, the resulting crack lengths on the edge of the diamond indentations would also lengthen. Despite this, the crack lengths on the edge of the diamond footprint were somewhat reduced, based on aforementioned microstructural refinement as well as reduction in the indentation footprint. More importantly, the laser shock peened surface rendered less prone to cracking, whereby, this improvement was not just driven by a microstructural refinement but also another mechanism such as the induction of compressive residual stress as further shown.

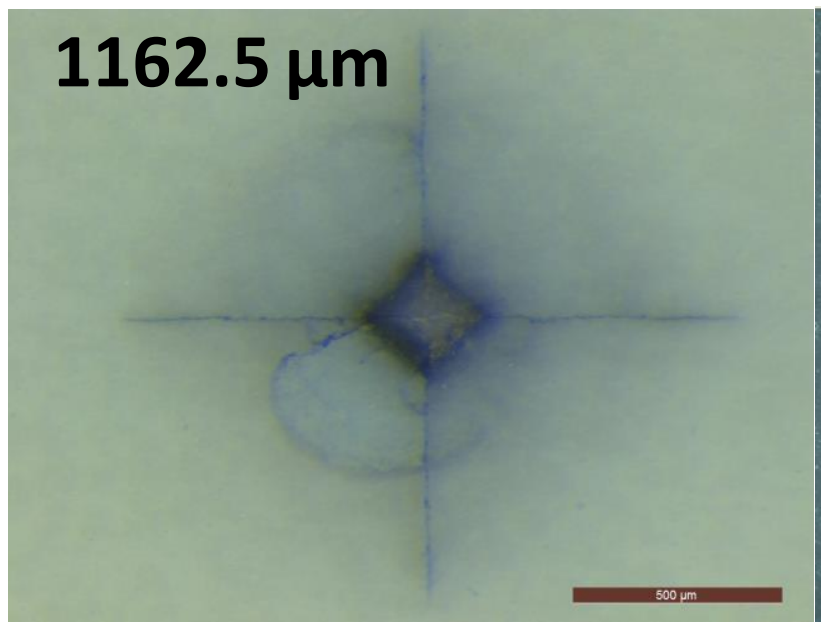

(a)

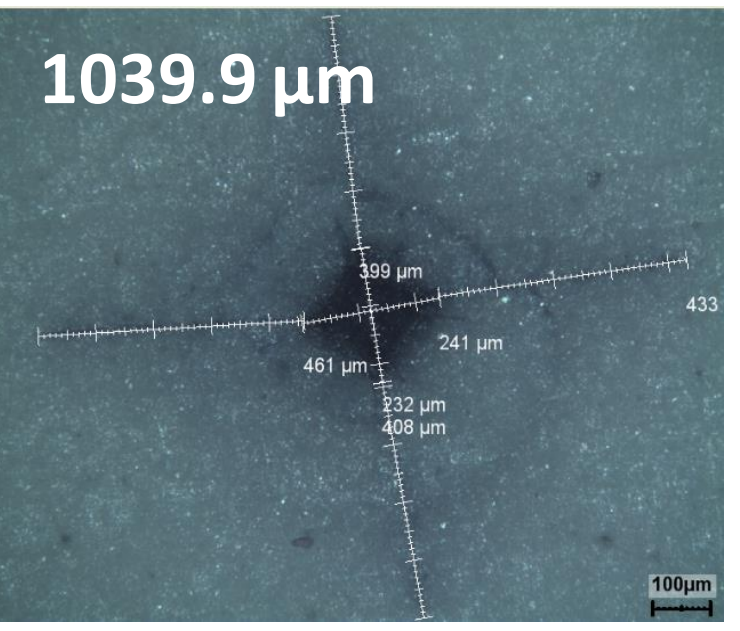

(b)

Figure 13 An example of the Vickers indentation replica comparing the flaw size of both the untreated surface in (a) and the laser shock peened surface in (b) of the $\mathrm{Al}_{2} \mathrm{O}_{3}$ armour ceramic. 


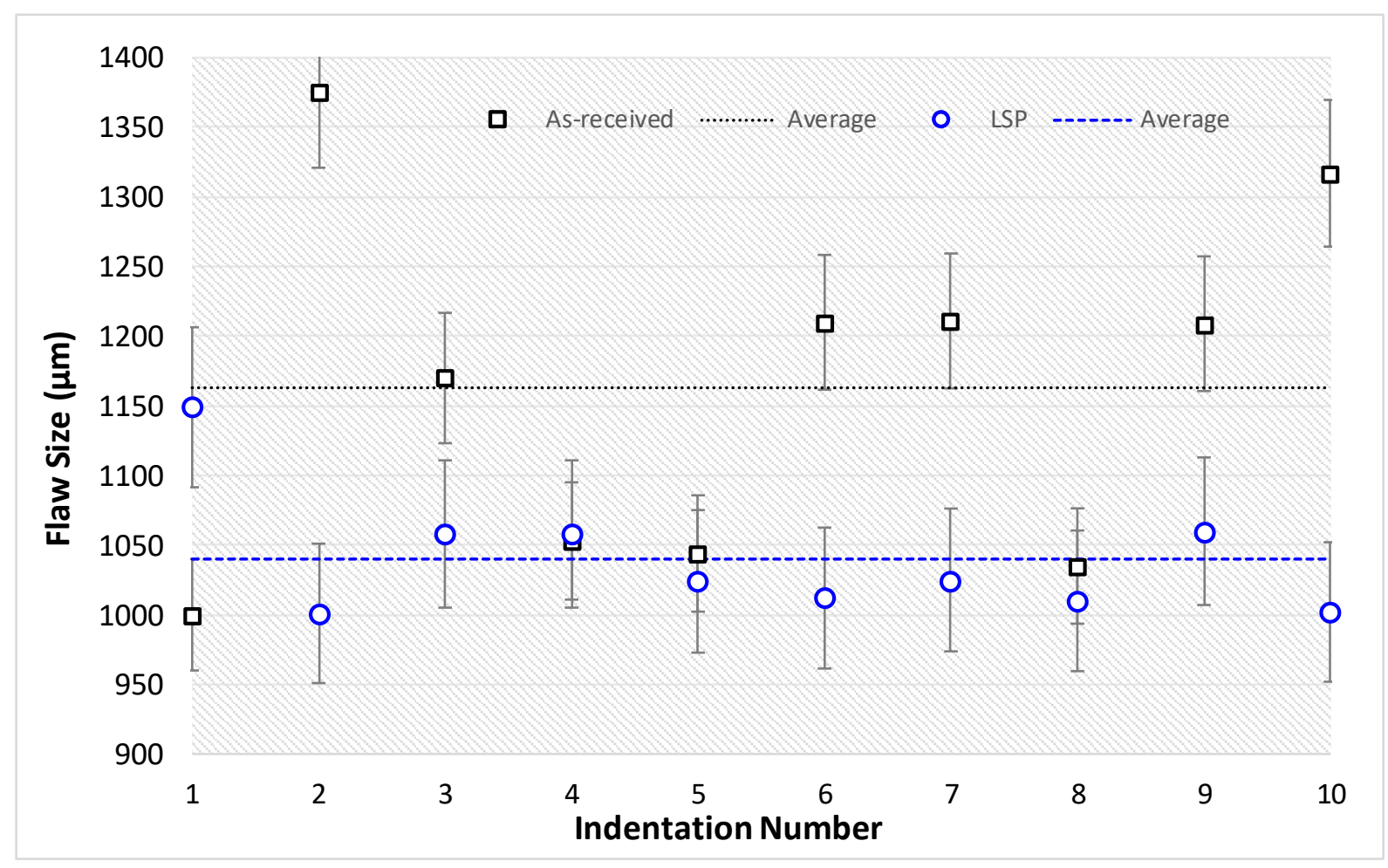

Figure 14 Examination of flaw sizes for the untreated and the laser shock peened $\mathrm{Al}_{2} \mathrm{O}_{3}$ Armour Ceramic.

\subsection{Fracture Toughness Modifications}

Figure 15 represents an example of the Vickers indentation replica comparing the $\mathrm{K}_{\mathrm{ic}}$ of both the untreated and the laser shock peened surfaces of the $\mathrm{Al}_{2} \mathrm{O}_{3}$ armour ceramic. The graph in Figure 16 demonstrates the modifications obtained in the $\mathrm{K}_{\mathrm{Ic}}$ for the laser shock peened surface of the $\mathrm{Al}_{2} \mathrm{O}_{3}$ ceramic armour and compared with it is the untreated surface. The average $\mathrm{K}_{\mathrm{lc}}$ of the untreated $\mathrm{Al}_{2} \mathrm{O}_{3}$ ceramic armour plate was $1.23 \mathrm{MPa} . \mathrm{M}^{1 / 2}$, whilst the lowest $\mathrm{K}_{\mathrm{lc}}$ was $0.94 \mathrm{MPa} . \mathrm{M}^{1 / 2}$ and the highest being $1.55 \mathrm{MPa} \cdot \mathrm{m}^{1 / 2}$. When the two different surfaces were compared, the highest and the lowest values above and below the mean were $1.5 \mathrm{MPa} \cdot \mathrm{m}^{1 / 2}$ and $1.13 \mathrm{MPa} \cdot \mathrm{m}^{1 / 2}$ with a mean of $1.4 \mathrm{MPa} \cdot \mathrm{m}^{1 / 2}$. On account of the analytical data and the results found, it can be said that the increase in $\mathrm{K}_{\mathrm{lc}}$ of $12 \%$ was attributed, firstly due to the increase in hardness, and secondly, due to the reduction in crack length. Lastly, an induction of elastic deformation and induced compressive residual stress as well as the microstructural refinement was also the cause for the change in $\mathrm{K}_{\mathrm{lc}}$. This is shown in the residual stress analysis in the following section. Both the crack length and hardness are input parameters of the equation to determine the $\mathrm{K}_{\mathrm{lc}}$. But increase in the hardness have caused the material being brittle, thus, crack length would also increase respectively. In this case, the crack lengths were reduced which indicated that compressive residual stress was a large factor as further demonstrated in the residual stress analysis. 


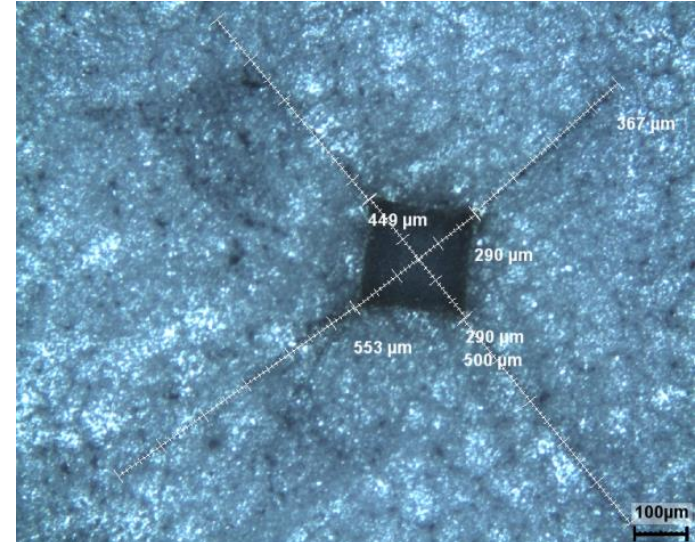

(a)

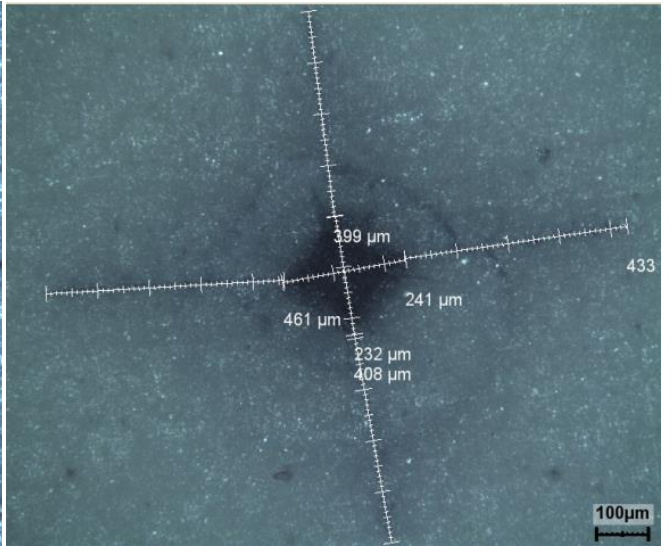

(b)

Figure 15 An example of the Vickers indentation replica, comparing the $K_{1 c}$ of both the untreated surface in (a) and the laser shock peened surfaces in (b) of the $\mathrm{Al}_{2} \mathrm{O}_{3}$ armour ceramic.

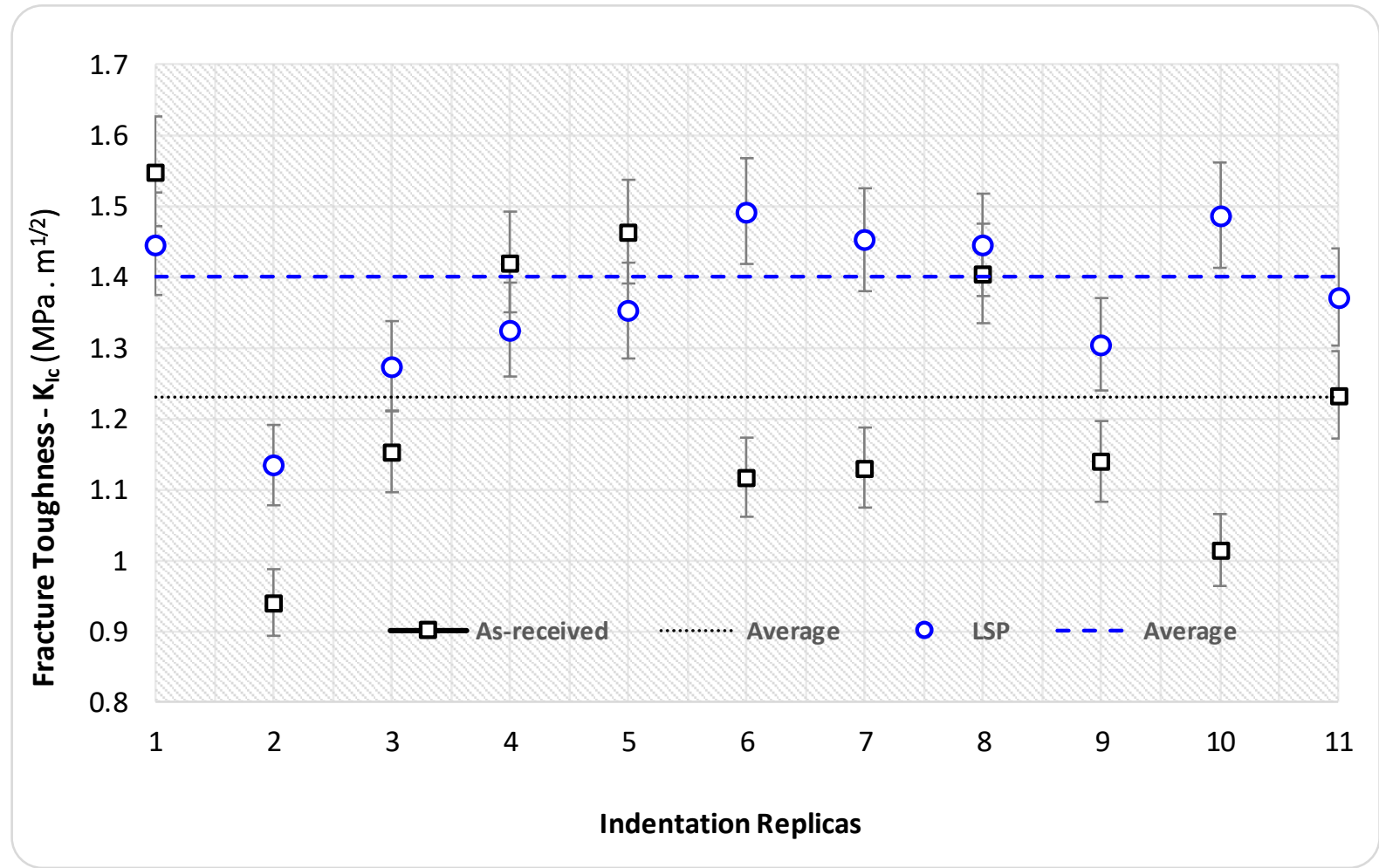

Figure 16 Examination of $\mathrm{K}_{l c}$ of the untreated and the laser shock peened $\mathrm{Al}_{2} \mathrm{O}_{3}$ Armour ceramics.

\subsection{Residual Stress Measurement using X-ray Diffraction Method}

Figure 17(a) and (b), and Figure 18 (a) and (b) showed the change in the d-spacing which is the value of strain with respect to the $\sin ^{2}$ psi values that were interpolated into values of stress. Figure 
19 showed stress values of the untreated surface of the $\mathrm{Al}_{2} \mathrm{O}_{3}$ ceramic armour plate. The surface yielded a stress value of $+180.7 \mathrm{MPa}$ with $\mathrm{a} \pm 20.8 \mathrm{MPa}$, whilst its shear stress was measured to be $-14.5 \mathrm{MPa}( \pm 9.6 \mathrm{MPa})$. This measurement was taken at $0^{\circ} \mathrm{Phi}$ angle and showed $6 \%$ reduction. With that said, the given error of \pm 18.8 (see Table 5 ) is not considerable and can be neglected. However, when this is compared to the measurements taken at $90^{\circ} \mathrm{Phi}$ angle, the results showed a value of $+219.3 \mathrm{MPa}( \pm 18.3 \mathrm{MPa})$ and a shear stress value of $-4.3( \pm 8.4 \mathrm{MPa})$. The untreated surface of the $\mathrm{Al}_{2} \mathrm{O}_{3}$ ceramic armour plate was in tension for both the surfaces. The residual stress after comparing the untreated surface with that of the laser shock peened surface of the $\mathrm{Al}_{2} \mathrm{O}_{3}$ ceramic armour plate was somewhat lower. At $0^{\circ} \mathrm{Phi}$ angle, the measured stress values yielded +169.5 ( $\pm 18.8 \mathrm{MPa})$ and a shear stress value of -27.0 ( \pm 8.7 MPa). Meanwhile, the stress values at $90^{\circ}$ Phi angle were measured to be $+155.2( \pm 17.7 \mathrm{MPa})$ and a shear stress of $-48.9 \mathrm{MPa}( \pm 8.2$ $\mathrm{MPa}$ ). Upon comparing the two surfaces, it can be gathered that a reduction in tensile stress took place after LSP surface treatment. Although the surface stress was in tension, the top near surface layer was relaxing after LSP surface treatment. This confirmed the change in hardness and also related to the microstructural modification as well as the Vickers indentation footprints, crack lengths, fracture toughness $\left(\mathrm{K}_{\mathrm{Ic}}\right)$, and finally the residual stress state. The relaxation of the $\mathrm{Al}_{2} \mathrm{O}_{3}$ ceramic armour in other words was being compressed via a local elastic/plastic deformation mechanism. In addition, the laser shock peened surface also became less prone to cracking, and in turn, enhanced its resistance to mechanical impact. Further refinement in the LSP process parameters would certainly yield better results in terms of residual stress which is currently under investigation by the leading author of this study. 


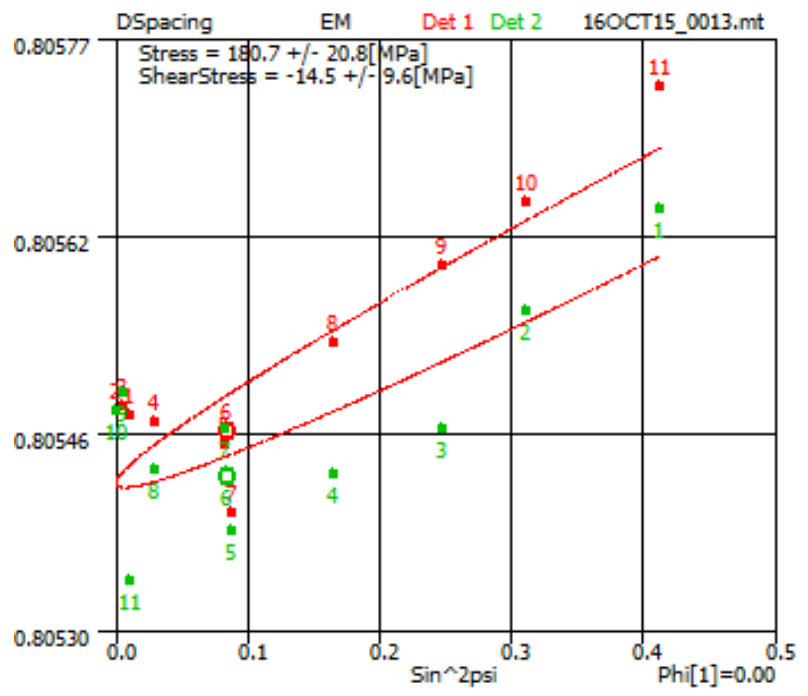

(a)

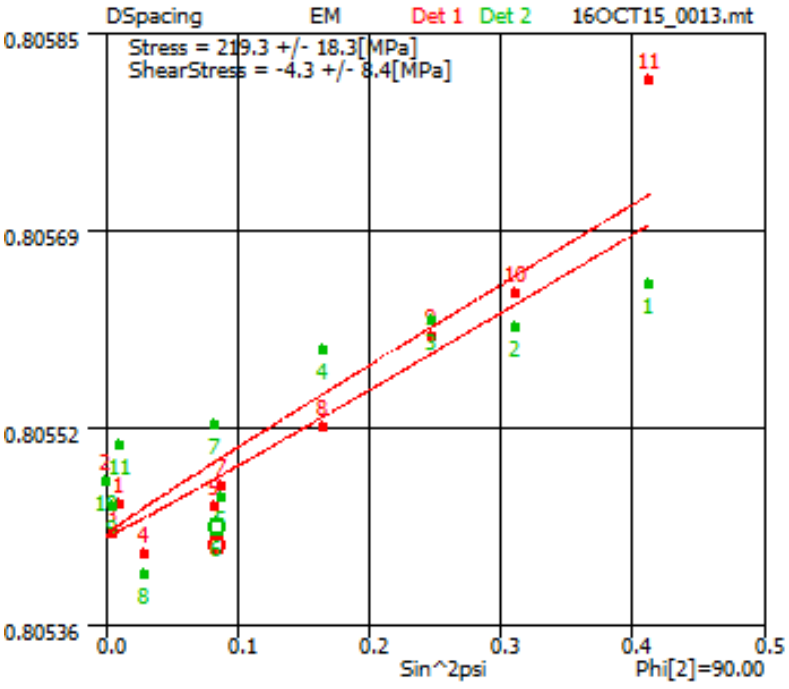

(b)

Figure 17 Residual stress state of the untreated $\mathrm{Al}_{2} \mathrm{O}_{3}$ ceramic armour plate in (a) at $0^{\circ}$ Phi angle and (b) at $90^{\circ}$ Phi angle.

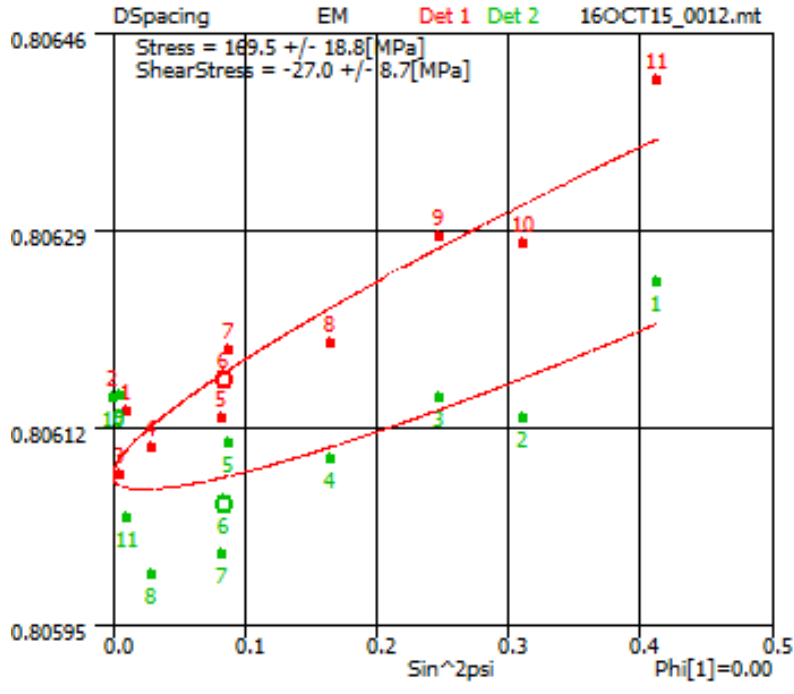

(a)

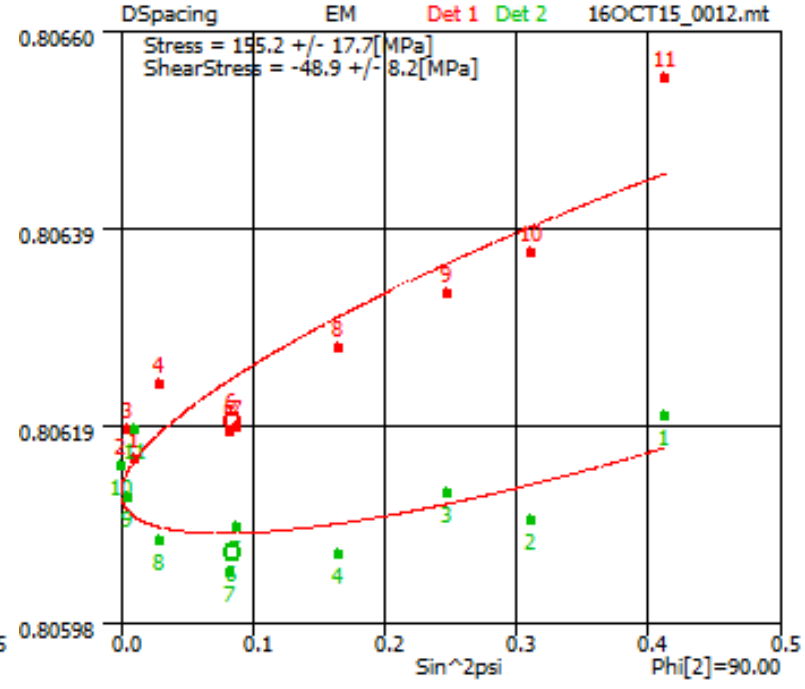

(b)

Figure 18 Residual stress state of the laser shock peened $\mathrm{Al}_{2} \mathrm{O}_{3}$ ceramic armour in at $0^{\circ}$ Phi angle in (a) and at $90^{\circ}$ Phi angle in (b). 
Table 5 Examination of residual stress using the $X$-ray diffraction method.

\begin{tabular}{|cccc|}
\hline Surface & Direction & Residual Stress $(\mathrm{MPa})$ & Modification \\
\hline Untreated & $0^{\circ}$ & $+180.7( \pm 20.8)$ & \\
\hline LSP & $0^{\circ}$ & $+169.5( \pm 18.8)$ & $6 \%$ reduction \\
\hline Untreated & $90^{\circ}$ & $+219.3( \pm 18.3)$ & $29 \%$ reduction \\
\hline LSP & $90^{\circ}$ & $+155.2( \pm 17.7)$ & \\
\hline
\end{tabular}

\subsection{Verification of Residual Stress State using Fluorescence Microscopy}

Residual stress was verified to confirm the results found from the XRD analysis. The fluorescence beam travelled from the untreated surface to the treated surface, as demonstrated in Figure 19. It can be seen from the untreated surface on the left of Figure 19 which demonstrated a tensile region. As the fluorescence beam traversed from the untreated to the laser shock peened surface, some compressive stress was observed which consequently begun to increase as the beam was further scanned over the laser shock peened zone. A maximum tensile stress on the untreated surface was found to be $163.49 \mathrm{MPa}$, whilst the highest compressive stress of $-49 \mathrm{MPa}$ was present on the same surface. The average residual stress over the untreated surface was in the region of 57MPa. After LSP, pockets of compressive stress were found with the highest being 172.38 MPa, whilst the highest tensile stress was 160.65 MPa. However, as one can see, the residual stress distribution over this region on the right-hand side of the graph has certainly demonstrated presence of compressive residual stress. Additional use of this technique will demonstrate a better understanding of the tensile stress being present on the surface of the laser shock peened region, but one explanation which can be given for this after comparison with the XRD results is that the beam employed for the XRD was of $2 \mathrm{~mm}$, whilst the fluorescence beam was only as small as $1 \mu \mathrm{m}$. This was a strong indication that the XRD beam was scanning a larger surface area and taking an average, whereas, the fluorescence beam was scanning a very small area in comparison which examined the pockets of not only compressive stress induced by LSP but also tensile stress that was pre-existing on the surface. The average of the residual stress on the laser shock peened zone was -78MPa which was considerably lower than the untreated surface of the $\mathrm{Al}_{2} \mathrm{O}_{3}$. This led to another indication, that the $\mathrm{Al}_{2} \mathrm{O}_{3}$ armour ceramic surface was being relaxed after the LSP surface treatment and this is why the aforementioned changes in the property had resulted. Moreover, it can also be suggested that the results of the XRD showed the 
same phenomenon taking place, whereby, the average examined stress by the XRD of the LSP regions showed surface relaxation as evident from the results of fluorescence data as well.

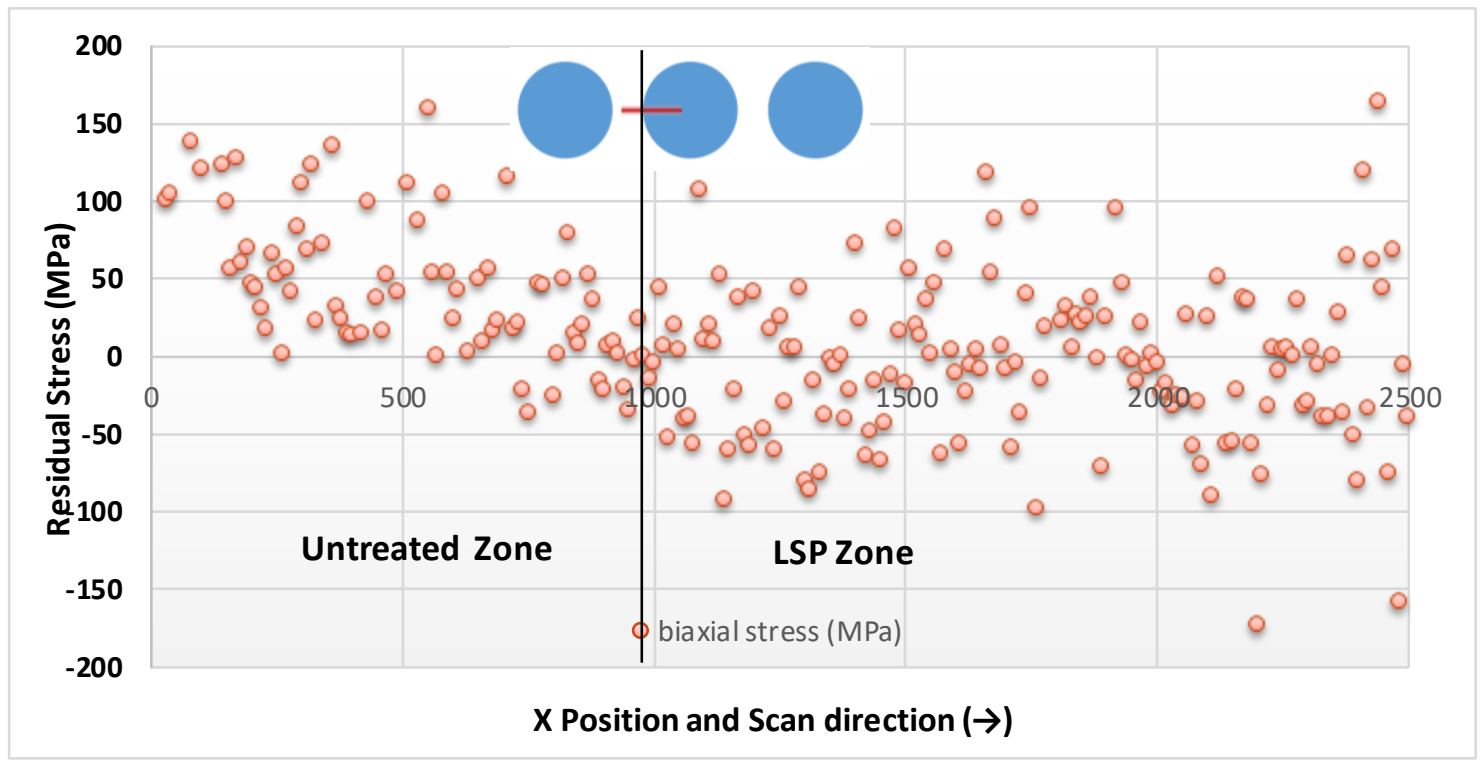

Figure 19 Distribution of residual stress from the untreated to the laser shock peened zones of the $\mathrm{Al}_{2} \mathrm{O}_{3}$ armour ceramics.

\section{Rationale for the Change in Hardness and Residual Stress State}

When the diamond indentation was induced into the ceramic, the response of the diamond indentation can vary for both the treated and the untreated surface. A better recovery of the indenter would result with the surface that was laser shock peened. Thus, a change in hardness had taken place between the laser shock peened and the untreated surfaces of the $\mathrm{Al}_{2} \mathrm{O}_{3}$ armour ceramic. At present, it is believed that the mechanism of change in hardness was as such that the compressive residual stress induced by the LSP surface treatment resisted the diamond indentation from penetration into the $\mathrm{Al}_{2} \mathrm{O}_{3}$ armour ceramic and produced a smaller foot-print and stopped the respective crack lengths from expansion, as shown from section 3.4 to 3.6 . In comparison, the untreated surface comprised of tensile stresses and had lower resistance to indentation, thus, created a larger foot-print and possibly a deeper penetration. Moreover, the crack geometry for this surface was larger than that of the surface that was laser shock peened and comprised of pre-existing tensile stress.

Generally, the enhancement in residual stress after LSP is directly related to increase in dislocation motion and its density. In addition, this is also backed by the microstructural refinement that would have started from the development of dislocation lines within the grains which then pile-up and create dislocation tangles, and ultimately, the transformation of dislocation piles and 
tangles into the sub-grain boundaries. Thereafter, the micro-structural evolution would lead to recrystallization in these sub-grain boundaries to refine the granular structure. This was somewhat evident from both the residual stress and micrographs illustrated herein, however, further study based on a qualitative and a qualitative mean is currently underway to understand the dislocation density and its generation within the $\mathrm{Al}_{2} \mathrm{O}_{3}$ armour ceramic before and after LSP surface treatment. It should also be noted that the parameters employed herein demonstrate some surface strengthening via enhancement in the surface properties, namely; hardness, fracture toughness as well as the fracture morphology around the Vickers indentation footprints through surface relaxation. If the laser induced spots were further optimized so that they are closer than $10 \mathrm{~mm}$ apart from each other and possibly overlapped (with of course no thermal shocking evident), then it is likely that the compressive stress induced relaxation has also increased. This means that the coverage of surface treatment should be increased to cover the whole area of the $50 \mathrm{~mm}$ by $50 \mathrm{~mm}$ armour tiles which would collectively not only enhance the impact resistance and the aforementioned properties, but also boost the bond strength after packaging and thus, contribute towards enhancing the ballistic performance of the ceramic armour in general.

Other investigations of hard brittle materials such as conventional silicate glasses, and some ceramics, have been strengthened using means of tempering and shot peening, whereby, compressive residual stresses were found up to four times $[67,68]$. These treatments could suppress the cracking that led to brittle fractures. In addition, shot peened bulk metallic glass also showed increase in plasticity during bending and in compression [67]. A combination of reduced surface cracking and more uniform deformation induced by some large amount of pre-existing shear bands (plastic-deformation mode in materials) and a combined mechanism different from any found in conventional engineering materials were also reported [67]. Furthermore, the work of Pfeiffer and Frey [68], reported that high compressive residual stresses up to 2GPa can be introduced into the near-surface of brittle ceramics and were exhibited via, micro-plastic deformation mechanism. Owing to this and the nature of experimental work conducted for LSP $\mathrm{Al}_{2} \mathrm{O}_{3}$ armour ceramics herein, we believe that the mechanism can be a combination of a possible of thermal-mechanical effect. The thermal effect is although very minimal due to no real change in the crystal phases of the $\mathrm{Al}_{2} \mathrm{O}_{3}$ ceramic as evident from the phase data (see Figure 6), where only corundum $\alpha$-phase was present prior-to and after LSP surface treatment. But, there was no tape used during LSP experimentation, and instead a black ink layer was employed so with application of 5 laser pulses on one surface area, the ink layer would have been removed completely from the first two pulses and the latter 3 pulses would have caused a level of heating, thus, producing a thermal effect. 
With that said, the latter 3 pulses applied to the $\mathrm{Al}_{2} \mathrm{O}_{3}$ armour ceramic produced minor level of ablation as reported in section 3.3 but more importantly, refined the microstructure and reduced the granular structure, leading to elastic + plastic deformation and localized areas of plastic deformation that governed some movement of dislocations and an increase in its density. In addition to this, our previous work on LSP of silicon carbide ceramic also suggested that the change in surface chemistry was one of the strong factors of increase in compressive residual stress and the respective properties [44]. This effect could also be possible on $\mathrm{Al}_{2} \mathrm{O}_{3}$ based ceramics after LSP treatment, but it still premature to rationalize the mechanism, thus, it leads to a pressing need to conduct further research focused on dislocation density, strain rate analysis and the composition changes with respect to residual stress state of such hard, brittle ceramics treated with LSP. 


\section{Conclusions}

LSP surface treatment of $\mathrm{Al}_{2} \mathrm{O}_{3}$ ceramic ballistic armour plate was conducted and surface characteristics were investigated from a mechanical and a micro-structural view-point for both the untreated and laser shock peened surfaces. The experimental conditions used and physical properties observation given, opens-up a variety of possibilities for further experimentation and analysis by other researchers. Additionally, this area of research is extremely valuable because it is a stepping-stone towards the improvement of the armour ceramics that is extremely topical in our current fight against terrorism. Based on the applied LSP conditions to the $\mathrm{Al}_{2} \mathrm{O}_{3}$ ceramic armour, a crack-free surface treatment was obtained by applying $2.5 \mathrm{~mm}$ spot size, $5 \mathrm{~Hz}$ frequency, $8 \mathrm{~ns}$ pulse duration, and energy of $78 \mathrm{~mJ}$ per pulse with 5 shots at a wavelength of $532 \mathrm{~nm}$. Characterization of the treated ceramic yielded a decrease in indentation size of $5 \%$ after LSP. This in turn led to an increase in hardness by $10 \%$. Also, a decrease in flaw size after the Vickers indentation tests showed a reduction in crack length by $10.5 \%$ after LSP despite the surface hardening which then increased the $\mathrm{K}_{\mathrm{lc}}$ by $12 \%$. The change in the surface mechanical property is also related to the micro-structure which showed grain refinement and a possible reduction in the grain size that could be directly attributed to the change in hardness. In addition, the analysis of residual stress state elucidated that despite the surface being in tension after LSP - a reduction in the surface stress at $0^{\circ} \mathrm{Phi}$ angle and $29 \%$ reduction at $90^{\circ} \mathrm{Phi}$ angle was examined. This was also confirmed and verified by the results obtained by florescence microscopy which also showed residual compressive stress of $-172 \mathrm{MPa}$ and pockets of compressive zones that also demonstrated surface relaxation on average. Both the residual stress results, thus, indicated the rationale behind the increase in hardness, a reduction in the crack lengths and the diamond indentation foot-prints, as well as some modification in the microstructure occurred as result of the induced compressive residual stress that was induced after LSP. A possible mechanism for the change in such mechanical and micro-structural characteristics was postulated as result of development of dislocations that create sub-grain boundary micro-structural evolution which lead to re-crystallization in these sub-grain boundaries to refine the granular structure. This ultimately lead to the generation of some elastic deformation of the $\mathrm{Al}_{2} \mathrm{O}_{3}$ ceramic armour plate leading to some strengthening as evidenced from the results herein. However, at this stage of research is is yet premature to confirm the mechanism behind such changes in the property, thus, further studies are focused on measuring these dislocation movement and density as well as the overall nature of armour strengthening using impact and ballistic strength examination are underway. The application of LSP for such armour products could not only lead to a superior impact and 
ballistic performance but in turn could help to save lives of end users and improve the performance of next generation armour products.

\section{Acknowledgement}

The leading author of this paper would like to thank the Engineering Physical Sciences Research Council (EPSRC) funded laser loan pool scheme and also the Science \& Technology Facilities Council (STFC) for granting a state-of-the-art system for Laser Shock Peening applications (Grant no: EP/G03088X/1, (13250017 - NSL4)), which was made and deployed for the first-time.

\section{Declaration of Interest}

It is confirmed that there are no actual or potential conflict of interest including any financial, personal or other relationships with other people or organizations within three years of beginning the submitted work that could inappropriately influence, or be perceived to influence, their work.

\section{References}

1. D. Richerson, D. W. Richerson, W.E. Lee, Modern Ceramic Engineering: Properties, Processing, and Use in Design, Third Edition. November 4, Tailor \& Francis by (CRC Press), Boca Raton, FL (USA), (2005), Textbook - 728 Pages.

2. P. Shukla, Viability and Characterization of Laser Surface Treatment of Engineering Ceramics, A doctoral Thesis. (2011), Loughborough University.

3. P. P. Shukla, and J. Lawrence, Evaluation of fracture toughness of $\mathrm{ZrO}_{2}$ and $\mathrm{Si}_{3} \mathrm{~N}_{4}$ engineering ceramics following $\mathrm{CO}_{2}$ and fibre laser surface treatment, Optics and Lasers in Engineering. 49(2) (2011) $229-239$.

4. P. P. Shukla, and J. Lawrence, Fracture toughness modification by using a fibre laser surface treatment of a silicon nitride engineering ceramic, Journal of Materials Science. 45(23) (2010) 6540-6555.

5. P. P. Shukla, and J. Lawrence, H. Wu, Fracture toughness of a Zirconia engineering ceramic and the effects thereon of surface processing with fibre laser radiation. Proceedings of the 
Institution of Mechanical Engineers, Part B, Journal of Engineering Manufacture, 224(B10) (2010) 1555-1570.

6. P. P. Shukla, and J. Lawrence, Modification of fracture toughness parameter $\mathrm{K}_{1 \mathrm{c}}$ following $\mathrm{CO}_{2}$ laser surface treatment of a $\mathrm{Si}_{3} \mathrm{~N}_{4}$ engineering ceramic, Surface Engineering. 27(10) (2011) $734-741$.

7. P. Shukla and J. Lawrence, Evaluation of Surface Cracks following Processing of a $\mathrm{ZrO}_{2}$ Advance Ceramic with $\mathrm{CO}_{2}$ and Fibre Laser Radiation, Advances in Ceramic Science and Engineering (ACSE). 2(4), (2013) 141-150.

8. L. R. Cook, W. J. Hampshire, and V. R. Kolarik, Ballistic Armour System, Appl. NO; 638,699, (1979), United States Patent.

9. M. Lee, and Y. H. Yoo, Analysis of ceramic/metal armour systems, International Journal of Impact Engineering 25 (2001) 819-829.

10. M. Cohen. And A. Israeli, Composite Armour Panels, United States Patent, (1998), Patent no: 5763813.

11. M. Medvedovski, Ballistic Performance of Armour Ceramics: Influence of design and structure. Part 1, Ceramics International. 26 (2010) $2103-2115$.

12. B. Matchen, Application of ceramics in armour products. Key engineering materials, in: $\mathrm{H}$. Mustaghasis (Ed.), Advanced ceramic materials 122 - 124, Trans. Tech. Publications. Switzerland (1996) 333- 342.

13. E. Medvedovski, Alumina Ceramics for ballistics protection, American Ceramic Society. $81(3)$ (2002) $27-32$. 
14. D. Triantafyllidis, L. Li, and F. H. Stott, Surface treatment of alumina-based ceramics using combined laser sources, Applied Surface Science. 176 (2002) 140-144.

15. D. Triantafyllidis, L. Li, and F. H. Stott, Crack-free densification of ceramics by laser surface treatment, Surface and Coating Technology. 210 (2006) $3163-3173$.

16. J. Lawrence, L. Li, and J. T. Spencer, Diode modification of ceramic material surface properties for improved wettability and adhesion, Applied Surface Science. 137-139 (1999) $377-393$.

17. J. Lawrence, and L. Li, Augmentation of the mechanical and chemical resistance characteristics of an $\mathrm{Al}_{2} \mathrm{O}_{3}$-based refractory by means of high power diode laser surface treatment, Journal of Materials Processing Technology. 142 (2003) $461-465$.

18. L. Sun, A. P. Malshe, W. Jiang, and P. H. Mccluskey, Effect of $\mathrm{CO}_{2}$ Laser Surface Processing on Fracture Behaviour of silicon Nitride Ceramic, Journal of Engineering Materials and Technology. 127 (2006) 460 - 467.

19. S. Polić, S. Ristić, J. Stašić, M. Trtica, B. Radojković, Studies of the Iranian medieval ceramics surface modified by pulsed tea $\mathrm{CO}_{2}$ and Nd:YAG lasers, Ceramics International. 41(1) Part A (2015) 85-100.

20. A.J. Harris, B. Vaughan, J.A. Yeomans, P.A. Smith, S.T. Burnage, Surface preparation of silicon carbide for improved adhesive bond strength in armour applications, Journal of the European Ceramic Society 33 (2013) 2925-2934.

21. H. J. Su, J. Zhang, Q. Ren, Y. F. Deng, L. Liu, L. H. Fu, A. K. Soh, Laser zone remelting of $\mathrm{Al}_{2} \mathrm{O}_{3} / \mathrm{Er}_{3} \mathrm{Al}_{5} \mathrm{O}_{12}$ bulk oxide in situ composite thermal emission ceramics: Influence of rapid solidification, Materials Research Bulletin 48(2) (2013) 544-550. 
22. A. H. Clauer, Laser hock peening for Fatigue Resistance, Surface Performance of Titanium, J. K. Gregory, H. J. Rack, and D. Eylon (eds.) TMS, Warrendale. PA (1996) 217-230.

23. I. Altenberger, E. A. Stach, G. Liu, R. K. Nalla, R. O. Ritchie, An in situ transmission electron microscope study of the thermal stability of near-surface microstructures induced by deep rolling and laser-shock peening. 48(12) (2003) 1593-1598.

24. S. R. Mannava, R. L. Yeaton, A. E. McDaniel, Dry tape covered laser shock peening, (1997), US Patents, 5674328.

25. D. Karthik, S. Kalainathan, S. Swaroop, Surface modification of 17-4 PH stainless steel by laser peening without protective coating process, Surface and Coatings Technology. 278 (2015) 138-145.

26. U. Trdan, J. A. Porro, J. L. Ocaña, J. Grum, Laser shock peening without absorbent coating (LSPwC) effect on 3D surface topography and mechanical properties of 6082-T651 Al alloy, Surface and Coatings Technology. 208 (2012) 109-116.

27. S. Prabhakaran, S. Kalainathan, Warm laser shock peening without coating induced phase transformations and pinning effect on fatigue life of low-alloy steel, Materials \& Design. 107 (2016) 98-107.

28. X. C. Zhang, Y. K. Zhang, J. Z. Lu, F. Z. Xuan, Z. D. Wang, S. T. Tu, Improvement of fatigue life of Ti-6Al-4V alloy by laser shock peening, Materials Science and Engineering: A. 527(15) (2010) 3411-3415.

29. Z. Bergant, U. Trdan, J. Grum, Effects of laser shock processing on high cycle fatigue crack growth rate and fracture toughness of aluminium alloy 6082-T651, International Journal of Fatigue. 87 (2016) 444-455. 
30. P. Shukla, G.C. Smith, D. G. Waugh, J. Lawrence. J, Development in Laser Peening of Advanced Ceramics, Proceedings of the SPIE. (2015) 9657 77-85.

31. K. Y. Luo, X. Jing, J. Sheng, G. F. Sun, Z. Yan, J. Z. Lu, Characterization and analyses on micro-hardness, residual stress and microstructure in laser cladding coating of $316 \mathrm{~L}$ stainless steel subjected to massive LSP treatment, Journal of Alloys and Compounds. 673 (2016) 158169.

32. J. Z. Lu, K. Y. Luo, F. Z. Dai, J. W. Zhong, L. Z. Xu, C. J. Yang, L. Zhang, Q. W. Wang, J. S. Zhong, D. K. Yang, Y. K. Zhang, Effects of multiple laser shock processing (LSP) impacts on mechanical properties and wear behaviors of AISI 8620 steel, Materials Science and Engineering: A (2012) 57-63.

33. J. Z. Lu, L. Zhang, A. X. Feng, Y. F. Jiang, G.G. Cheng, Effects of laser shock processing on mechanical properties of Fe-Ni alloy, Materials \& Design. 30(9) (2009) 3673-3678.

34. J.Z. Lu, J.S. Zhong, K.Y. Luo, L. Zhang, H. Qi, M. Luo, X.J. Xu, J.Z. Zhou, Strain rate correspondence of fracture surface features and tensile properties in AISI304 stainless steel under different LSP impact time, Surface and Coatings Technology. (2013) 221 88-93.

35. H. Lim, P. Kim, H. Jeong, S. Jeong, Enhancement of abrasion and corrosion resistance of duplex stainless steel by laser shock peening, Journal of Materials Processing Technology. 212(6) (2012) 1347-1354.

36. A. Telang, A. Amrinder, S. Gill, S. Teysseyre, S. R. Mannava, D. Qian, V. K. Vasudevan, Effects of laser shock peening on SCC behavior of Alloy 600 in tetrathionate solution, Corrosion Science. 90 (2016) 434-444.

37. X. Chen, X. Fang, S. Zhang, J. F. Kelleher, J. Zhou, Effects of LSP on micro-structures and residual stresses in a 4 mm CLAM steel weld joints, Fusion Engineering and Design. 94 (2015) 54-60. 
38. K.Y. Luo, B. Liu, L.J. Wu, Z. Yan, J.Z. Lu, Tensile properties, residual stress distribution and grain arrangement as a function of sheet thickness of Mg-Al-Mn alloy subjected to two-sided and simultaneous LSP impacts, Applied Surface Science. 369 (2016) 366-376.

39. X. Chen, J. Wang, Y. Fang, B. Madigan, G. Xu, J. Zhou, Investigation of microstructures and residual stresses in laser peened Incoloy $800 \mathrm{H}$ weldments, Optics \& Laser Technology. 57 (2016) 159-164.

40. Y. Shadangi, K. Chattopadhyay, S. B. Rai, V. Singh, Effect of LASER shock peening on microstructure, mechanical properties and corrosion behavior of interstitial free steel, Surface and Coatings Technology. 280 (2015) 216-224.

41. Nikola Kalentics, Eric Boillat, Patrice Peyre, Cyril Gorny, Christoph Kenel, Christian Leinenbach, Jamasp Jhabvala, Roland E. Logé, 3D Laser Shock Peening - A new method for the 3D control of residual stresses in Selective Laser Melting, Materials \& Design, 130, 15, 2017, 350-356.

42. A. Koichi, Y. Sano, A. Kazuma, T. Hirotomo, I. O. Shin, Strengthening of $\mathrm{Si}_{3} \mathrm{~N}_{4}$ Ceramics by Laser Peening, Residual Stresses VII. ECRS7, 524 - 525 (2006) 141-146.

43. P. P. Shukla, T. P. Swanson, C. J. Page, Laser Shock Peening and Mechanical Shot Peening Processes Applicable for the Surface Treatment of Technical Grade Ceramics: A Review, Proceedings of the Institution of Mechanical Engineers Part B: Journal of Engineering Manufacture. 228(5) (2014) $639-652$.

44. P. Shukla, S. Nath, W. Wang, X. Shen, J. Lawrence, (2017), Surface property modifications of silicon carbide ceramic following laser shock peening, Journal of European Ceramic Society, 37(9), 1728 - 1739.

45. P. Shukla, J. Lawrence, Y. Zhang, Understanding Laser-beam brightness: A Review on a New Prospective in Materials Processing. Optics and Lasers in Engineering, 75, (2015) 40 - 51.

46. I. J. McColm, Ceramic Hardness, Platinum Press. (1990), New York, NY. 
47. C. B. Ponton, R. D. Rawlings, Vickers indentation fracture toughness test. Part 1. Review of literature and formulation of standardized indentation toughness equations, Materials Science and Technology. 5(9) (1989a) 865 - 872.

48. C. B. Ponton, R. D. Rawlings, Vickers indentation fracture toughness test. Part 2. Application and critical evaluation of standardized indentation toughness equations, Materials Science and Technology. 5(10) (1989b) $961-976$.

49. B. R. Lawn, and M. V. Swain, Microfracture: Beneath Point In- dentations in Brittle Solids. Journal of Material Science 10, (1975) 113 - 122.

50. B. R. Lawn, and E. R. Fuller, Equilibrium penny-like cracks in indentation fracture. Journal of Material Science 10, (1975) 2016 - 2024.

51. A. G. Evans, Wilshaw TR Quasi static particle damage in brittle solids. Acta Metal, 24, (1976) $939-956$.

52. B. R. Lawn, and A. G. Evans, and D. B. Marshall, Elastic/ Plastic Indentation Damage in ceramic: The Meadian/ Radial Crack System. Journal of American Ceramic Society 63 (1970) $9-10,574-571$.

53. K. Niihara, R. Morena, D. P. H. Hasselman, Evaluation of $\mathrm{K}_{1 \mathrm{c}}$ of brittle solids by the indentation method with low crack-to-indent ratios. Journal of material Science Literature 1, (1972) 13 16.

54. J. Lankford, Indentation micro-fracture in the Palmqvist crack regime: implication for fracture toughness evaluation by the indentation method. Journal of Material Science Letters 1 (1972) 493-495.

55. K. Tanaka, Elastic/plastic indentation hardness and indentation fracture toughness: The inclusion core model. Journal of Material Science 22 (1977) 1501 - 1507. 
56. G. R. Anstis, P. Chantikul, B. R. Lawn, D. B. Marshall, A critical evaluation of indentation technique for measuring fracture toughness, I, direct measurement. Journal of American Ceramic Society 64, (1970) $533-537$.

57. E. O. Hall, The Deformation and Ageing of Mild Steel: II Characteristics of the Lüders Deformation, Proceedings of Physical Society, London B (1951); 64:747.

58. A. Rothman, S. Kalabukhov, N. Sverdlov, M. P. Dariel, N. Frage, (2012) International Journal of Applied Ceramic Technology, 1:11.

59. M. Trunec, (2008) Ceramics—Silikáty 52:165.

60. B. Ahmad, M. E. Fitzpatrick, The effect of laser shock peening on hardness and microstructure in a welded marine steel, The Journal of Engineering. Volume July 2015 (2015) PP 1 - 11.

61. A. Milosavljevic, S. Petronic, A. Kovacevic, Z. Kovacevic, Z. Stamenic, Laser Shock Peening of N-155 Superalloy After Longtime Service, Tehnički vjesnik. 20(2) (2013) 323-327.

62. H. Qiao, J. Zhao, Y. Gao, Experimental investigation of laser peening on TiAl alloy microstructure and properties, Chinese Journal of Aeronautics. 28(2) (2015) Pages 609-616.

63. D. Karthik, and S. Swaroop, Influence of Laser Peening on Phase Transformation and Corrosion Resistance of AISI 321 steel, Science Journal of Materials Engineering and Perform. (2016) 25: 2642.

64. M. Rozmus, J. Kusinski, M. Blicharski, J. Marczak, Laser Shock Peening of a Ti6Al4v Titanium Alloy, Archives of Mettalurgy and Materials. 54(3) (2009) 665 - 670.

65. Y. Zhang, J. Lu, K. Luo, Laser Shock Processing of FCC Metals: Mechanical Properties and Microstructural Strengthening Mechanism (2013) Springer - Verlag, Heidelberg, Berlin.

66. British Standards. Vickers hardness test, - Part 2, Verification and calibration of testing machines. Metallic Materials - ISO6507-1, (2005). 
67. Y. Zhang, W. H. Wang and A. L. Greer, Makingmetallic glasses plastic by control of residual stress, Nature Materials Letters, (2006), 857 - 860.

68. R. Gardon, In Elasticity and Strength in Glasses (eds Uhlmann, D. \& Kreidl, N. J.) 145-216 (Glass: Science and Technology, Vol. 5, Academic, New York, 1980).

Citation: Shukla, P., Robertson, S., Wu, H., Telang, A., Kattoura, M., Nath, S., Mannava, S.R., Vasudevan, V.K., and J. Lawrence, (2017), 'Surface Engineering Alumina Armour Ceramics with Laser Shock Peening', Materials and Design, 134, 523 - 538. 
